\title{
FANatics: Systematic literature review of factors associated with celebrity worship, and suggested directions for future research
}

\author{
Samantha K. Brooks ${ }^{1}$ (D) \\ Published online: 26 September 2018 \\ (C) The Author(s) 2018
}

\begin{abstract}
A 'culture of celebrity' began to emerge in the twentieth century, profoundly impacting the social world. Recent years have seen the publication of an increasing wealth of literature focusing on people who are enthralled with celebrities - often to the point of obsession - termed 'celebrity worshippers'. The current paper systematically reviews this literature to gain a comprehensive understanding of the various factors associated with celebrity worship and to identify gaps in the literature. Papers were identified through a systematic literature search and 62 were deemed relevant for inclusion in the review. These provided evidence that celebrity worship may be related to demographic factors (e.g. age); personality factors (e.g. dimensions of the psychoticismextraversion-neuroticism model, materialism); religiosity; behavioural and cognitive-behavioural factors (e.g. fantasy proneness, obsessive behaviours); feelings about the self or the world (e.g. self-esteem); cognitive factors (e.g. cognitive flexibility, critical thinking); relationships with others (e.g. attachment style, romantic relationship style); attitudes towards the body, eating, and cosmetic surgery; and psychological wellbeing (e.g. depression, anxiety). The results are used to help researchers understand the individual and psychosocial factors associated with celebrity worship, and directions for future research in this area are identified.
\end{abstract}

Keywords Celebrities $\cdot$ Celebrity worship $\cdot$ Fans $\cdot$ Idolisation $\cdot$ Literature review $\cdot$ Systematic review

\section{Introduction}

The proliferation of the media and rise of 'celebrity culture' in the late twentieth century has led psychologists to begin exploring the meanings that celebrities have in the lives of their audiences. Media personalities can be powerful agents of social change (Brown 2015), and the media frequently relies on the public's fascination with - and desire to be like - celebrities in order to influence the public. Many studies have explored how celebrities can shape attitudes, behaviours and beliefs for example, how they might encourage purchasing behaviours (Malik and Guptha 2014; Wang et al. 2013), influence political views (Austin et al. 2008; Veer et al. 2010) or endorse health-related messages (Brown and Basil 1995; Casey et al. 2013; Chapman et al. 2005; Kosenko et al. 2016). There is evidence to suggest that the stronger the attachment to the celebrity in question, the more likely a fan is to adopt the

Samantha K. Brooks

samantha.k.brooks@kcl.ac.uk

1 Department of Psychological Medicine, Weston Education Centre, King's College London, Cutcombe Road, Denmark Hill, London SE5 9RJ, UK messages promoted by the celebrity (Basil 1996; Brown and de Matviuk 2010; Chung and Cho 2017).

More recently, research has considered fans' attachments to their favourite celebrities; these (typically one-sided) relationships are taken very seriously and seen as central to the identities and emotional lives of fans (Hackley and Hackley 2016). The closeness one might feel toward their favourite celebrity is a 'parasocial attachment', i.e. a one-way relationship resulting from a false sense of intimacy created during media consumption (Horton and Wohl 1956). It has been suggested that becoming emotionally attached to celebrities is common and unsurprising (Brown 2015; Stever 2017), perhaps due to the Media Equation (Reeves and Nass 1996), which suggests human perceptions do not differentiate between those from the real world and those from media. Many researchers recommend viewing parasocial relationships with celebrities as an extension of normal, everyday social interaction not dissimilar to real relationships (Branch et al. 2013; Giles 2002; Greenwood et al. 2008), and attachment to celebrities as a normal part of development in the areas of intimacy and identity (Greene and Adams-Price 1990; Stever 2011a; Larson 1995).

However, sometimes this sense of attachment can become extreme, and research has begun to focus on the concept of 
'celebrity worship' (referred to hereafter as CW), a form of almost obsessional involvement where individuals idolise their favourite celebrity to the point of 'worship'. Some authors liken the concept of CW to religious worship, with the celebrity reaching - in the fan's mind - the kind of status usually reserved for a deity, and fan behaviour often mimicking religious practices (Giles 2000; Liu 2013). Religious connotations are frequently invoked in discourse around celebrities, which sees celebrities referred to as 'idols' or 'icons' (Alexander 2010; Hackley and Hackley 2016); the word 'fan' itself originates as an abbreviation for 'fanatic', a term describing extreme enthusiasm typically inspired by a deity (Leets et al. 1995).

Brown (2015) describes CW as an intense form of psychological attachment which involves making one's relationship with their favoured celebrity the primary focus of their life, evolves from strong identification with and intense devotional feelings for that persona, and is characterised by loyalty and willingness to invest time and finances into that person. Hollander (2010) suggests the motivations for CW are attempts to identify with someone who possesses attributes which are lacking in the life of the worshipper; insecurity about social status and uncertainty about what qualities are worthy of admiration; and social isolation resulting in a desire to find vicarious meaning in the lives of others. Redmond (2016) cites attraction, empathy, longing, belonging and emulation as factors associated with feeling connected to certain celebrities, while Wann (1995) suggests that sport CW in particular is motivated by needs for stimulation, self-esteem, escape, entertainment, aesthetics, and group affiliation.

McCutcheon et al. (2002) proposed a model of CW based on psychological absorption and addiction, suggesting fans with weak identity structures and a lack of meaningful relationships may try to establish a solid identity and gain a sense of fulfilment by becoming psychologically 'absorbed' in their favourite celebrity. The absorption-addiction model suggests that the dynamics involved in the motivations driving this resemble those of addiction, in that celebrity worshippers may develop a tolerance for behaviours that initially satisfied their need for absorption which can lead to the relationship with the favoured celebrity becoming an addiction. The model suggests that $\mathrm{CW}$ advances through three stages: first, celebrity worshippers may move beyond absorption to seek out other fans as sources of information about their favoured celebrity. Then, those with a higher capacity for absorption may seek to become more intimately involved with aspects of celebrities' lives; a further increase in the thresholds of the need and capacity for absorption can lead to individuals overidentifying with celebrities and becoming obsessional about their lives. Celebrity worshippers may progress along this hierarchy due to developing a tolerance to the milder levels of CW and needing to reach the deeper, more pathological levels in order to satisfy the addiction. This is likely to occur over time, and only for some celebrity worshippers; others may remain at the lower levels.

The most frequently used measure of $\mathrm{CW}$ is the Celebrity Attitude Scale (CAS; McCutcheon et al. 2002). Factor analysis of the CAS has led to the identification of three dimensions of CW. The lowest level of worship, the 'entertainment-social' level, suggests fans are attracted to a celebrity due to their entertainment value and being a source of social interaction with others. This level involves talking with others about favourite celebrities and following their lives through social media, motivated mostly by sensation-seeking and entertainment. The entertainment-social subscale of the CAS comprises ten items, such as I love to talk with others who admire my favourite celebrity and Keeping up with news about my favourite celebrity is an entertaining pastime, which participants rate on a scale of 1 ('strongly disagree') to 5 ('strongly agree'). The intermediate level, the 'intense-personal' dimension of $\mathrm{CW}$, reflects more intense feelings towards the favoured celebrity and increasing absorption in their personal life, where the fan may begin to 'exist in and for the celebrity that is adored' (Redmond 2016, p.240). This subscale comprises nine items, such as I consider my favourite celebrity to be my soul mate and When something good happens to my favourite celebrity I feel like it happened to me. The most extreme level of CW is the 'borderline-pathological' level, typified by over-identification with the celebrity, willingness to do almost anything to please them, and delusional fantasies about them. This subscale comprises four items, including If I was lucky enough to meet my favourite celebrity, and he/she asked me to do something illegal as a favour, I would probably do it. There appears to be a hierarchical trend whereby entertainment-social CW tends to be most common, followed by intense-personal and then borderline-pathological (Green et al. 2014; Maltby and Day 2011; Maltby et al. 2004a, 2011; McCutcheon et al. 2016a, 2016b; Swami et al. 2011a; Vega et al. 2013).

A fourth factor of the CAS has also been suggested - 'deleterious imitation', referring to willingness of fans to imitate licentious behaviour of their favourite celebrity. This concept was introduced by North and Hargreaves $(2005,2006)$ and two studies have suggested this may be an additional factor of the CAS (North et al. 2007; Sheridan et al. 2007). However, the majority of studies using the CAS have focused on the entertainment-social, intense-personal and borderlinepathological levels of $\mathrm{CW}$ as it is these three dimensions which most frequently emerge from factor analysis.

The internal reliability of the CAS appears to be high; Cronbach's alpha reliability coefficients for the CAS as a whole generally range between .84 and .94 (McCutcheon et al. 2006a). Alphas for the borderline-pathological scale tend to be lower (McCutcheon et al. 2006a) perhaps because this sub-scale is the shortest of the three, comprising few items. 
Griffith et al. (2013) examined the test-retest and internal reliability of the CAS, finding that attitudes about celebrities were fairly stable over a period of three months. The authors suggest this provides evidence of $\mathrm{CW}$ being resistant to change, although one could argue that participants should be assessed over a longer interval to truly ascertain whether CW is a lasting phenomenon.

\section{Aims}

The concept of CW is one which has only recently attracted academic attention, and as such our understanding of it is limited. Although several articles (Giles and Maltby 2006; Hyman and Sierra 2010; Sansone and Sansone 2014) provide a general overview of CW studies, until now there has been no systematic literature review on the topic. The current review aimed to fill this gap by providing a comprehensive overview of all published literature exploring factors associated with $\mathrm{CW}$, and proposing directions for future research.

\section{Method}

\section{Study Selection}

To be included in the review, studies had to: i) include primary data; ii) be published in an academic journal; iii) be written in English; iv) report on factors associated with $\mathrm{CW}$; and v) include a measure of CW (e.g. the CAS) or a self-report of celebrity idolisation or include a type of behaviour indicative of potential CW (e.g. membership to a fan-club).

The search strategy used a combination of Search 1 ('celebrity' or 'celebrities' or 'public figure*' or 'idol*') and Search 2 ('worship*') to search the following databases: OVID MEDLINE®, PsycArticles, PsycINFO®, Social Policy and Practice, and Social Sciences Citation Index. Resulting citations were downloaded to EndNote(C) software version X7 where duplicates were automatically removed. The titles of all citations were evaluated for their relevance to the topic. Next, the inclusion criteria were used to screen abstracts of remaining citations and exclude any clearly irrelevant papers. Full texts of the remaining citations were then obtained; the majority of these were available online, and in cases where they were not, corresponding authors were contacted. These papers were read in their entirety, with any not meeting the inclusion criteria excluded. The reference lists of all remaining papers were hand-searched for relevant papers which may have been missed.

\section{Data Extraction and Synthesis}

A spreadsheet was designed to systematically extract data from papers. Information extracted included authors; publication year; country of study; design; participant information ( $n$, age, gender); measure of $\mathrm{CW}$; factors investigated and how they were measured; and key results.

Inductive thematic analysis (Braun and Clarke 2006) was used to analyse the results of the studies and group common factors associated with $\mathrm{CW}$ into a typology. Data was first coded broadly, and used to develop descriptive themes (e.g. all data on age or gender was coded as 'demographics'). Studies reporting non-significant findings were also included, to provide a balanced view of the literature.

\section{Results}

A total of 422 citations were found via the initial search and imported into EndNote $($, along with an additional 16 papers identified via hand-searching. A total of 62 papers were deemed relevant for inclusion in the review. Details of the number of papers excluded at each stage are presented in the PRISMA diagram (Moher et al. 2009) (Fig. 1).

The majority of papers were from the USA $(n=22)$, UK $(n=18)$ or Asia $(n=15)$ or a combination of the three $(n=3)$. The remaining studies included participants from various countries across Europe, North America, Australia and New Zealand. Population sizes in the studies ranged from 61 to 1641 participants. Most used the Celebrity Attitude Scale (CAS) as a measure of CW; other scales included the Idol Worship Questionnaire (Yue and Cheung 2000), Expression of Idolization Scale (Raviv et al. 1996), Obsessive Relational Intrusion and Celebrity Stalking Scale (McCutcheon et al. 2006b), a short form of the Relationship Rating Form (Fraley and Davis 1997) to assess relationships with celebrities, the Public Figure Preoccupation Inventory (Sheridan et al. 2006) and unique scales developed for the specific studies. An overview of all included papers is presented in Table 1.

Results were grouped into a number of core themes, which are discussed individually below. Any factors identified by at least two papers are discussed within relevant sub-themes; factors identified by only one paper are grouped together under 'other' within each sub-theme.

\section{Demographics}

\section{Age}

Several studies showed a negative correlation between age and CAS scores (Ashe and McCutcheon 2001; Houran et al. 2005; Maltby et al. 2005; Swami et al. 2011a). Raviv et al. (1996) found that idolisation of celebrities was strongest in early adolescence (age 10-11), while Giles and Maltby (2004) found that CW reached its peak in middle adolescence. Potentially related, McCutcheon et al. (2006a) found that older participants were less likely to endorse 'stalking 
Fig. 1 PRISMA diagram

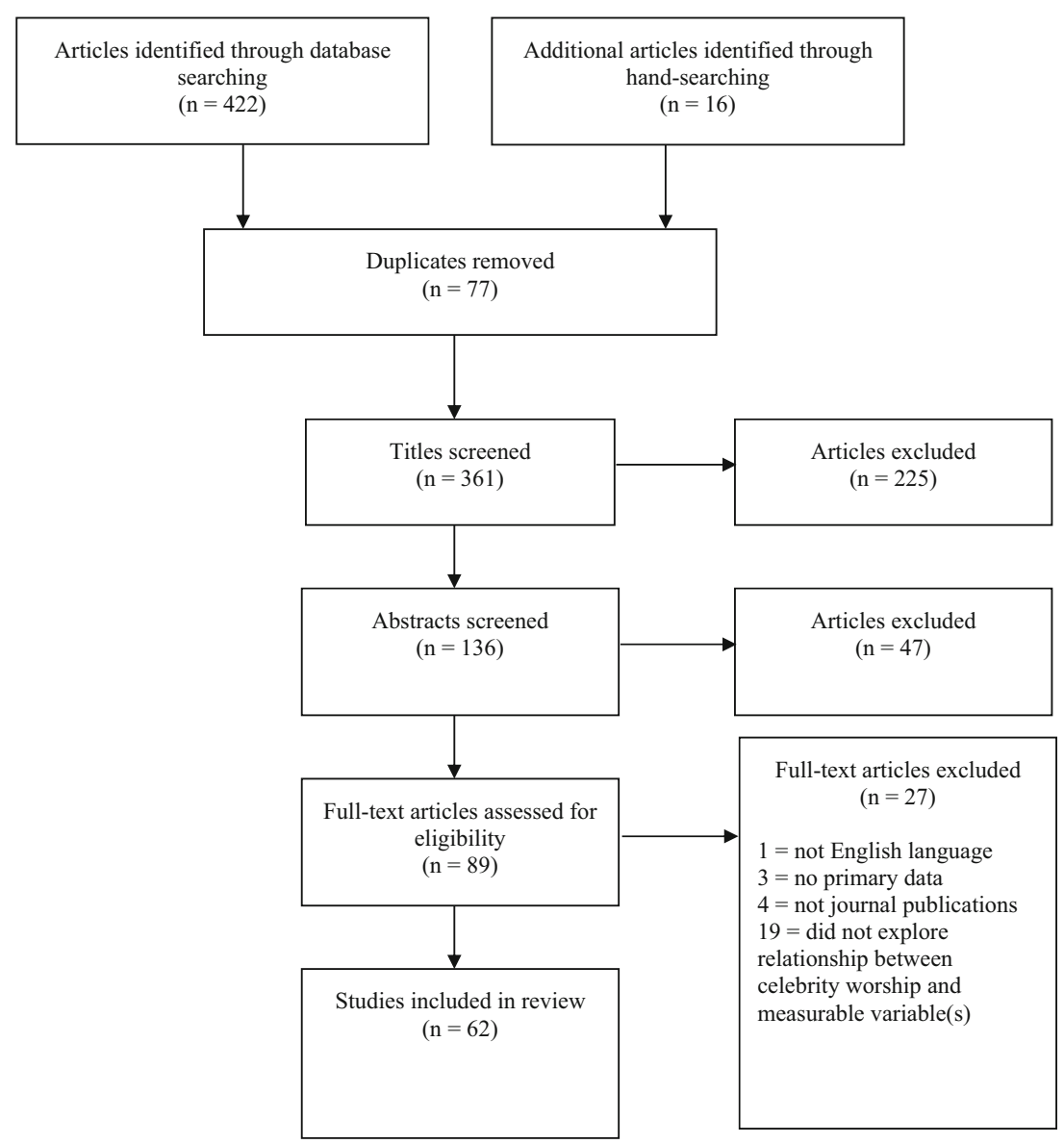

behaviours' towards celebrities; however Chia and Poo (2009) reported that borderline-pathological $\mathrm{CW}$ was more common in older adolescents than younger. In a study of adults only, Swami et al. (2011b) found a positive correlation between intense-personal $\mathrm{CW}$ and age, and negative correlations between age and both entertainment-social and borderlinepathological CW. Three studies of adults only (Maltby et al. 2004a, 2006; McCutcheon and Richman 2016) reported no significant relationship between $\mathrm{CW}$ and age.

\section{Gender}

Raviv et al. (1996) and Cheung and Yue (2003a, 2011) found that idolisation of celebrities was more prevalent among females than males. Several studies reported that females scored higher than males on the CAS overall (Huh 2012), the entertainment-social subscale (Swami et al. 2011a; Vega et al. 2013), or the intense-personal subscale (Liu 2013; Maltby et al. 2004b), while males reported higher levels of borderline-pathological CW (Chia and Poo 2009; Maltby et al. 2004a; Reeves et al. 2012). McCutcheon et al. (2016c) found higher levels of both entertainment-social and intensepersonal CW for males, while North et al. (2005) found higher levels of intense-personal and borderline-pathological CW among males. Perhaps related, McCutcheon et al. (2006a) found that males were slightly more likely to endorse celebrity stalking. Conversely, Maltby et al. (2004b) reported that females in a student sample scored higher on borderlinepathological CW, while Reeves et al. (2012) found that males scored higher on total CAS scores and the entertainmentsocial subscale. However, many studies (Ashe et al. 2005; Giles and Maltby 2004; Maltby and Day 2011; Maltby et al. 2001, 2002, 2003, 2005, 2006, 2011; McCutcheon 2002; McCutcheon et al. 2003, 2015) found no difference in CAS scores between genders.

\section{Culture}

Jung and Hwang (2016) found that US participants showed greater CW than South Koreans, while McCutcheon et al. (2017) found that Indian participants scored significantly higher on all three subscales of the CAS than participants from the USA. McCutcheon et al. (2014a) found that Jamaican participants scored significantly higher on borderlinepathological $\mathrm{CW}$ than participants from Barbados. McCutcheon et al. (2016c) found that Belizeans scored significantly higher than Americans on intense-personal CW. 


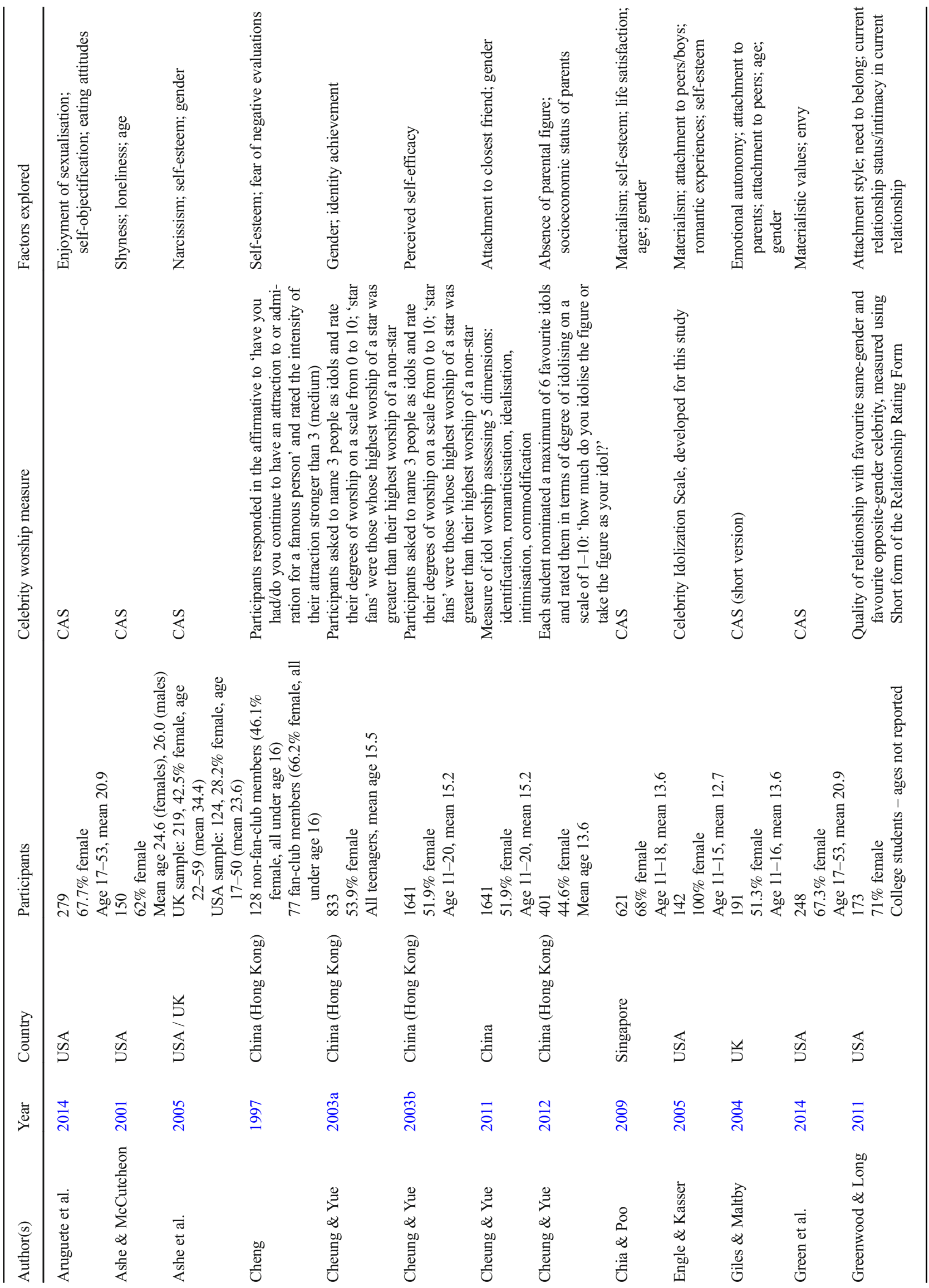




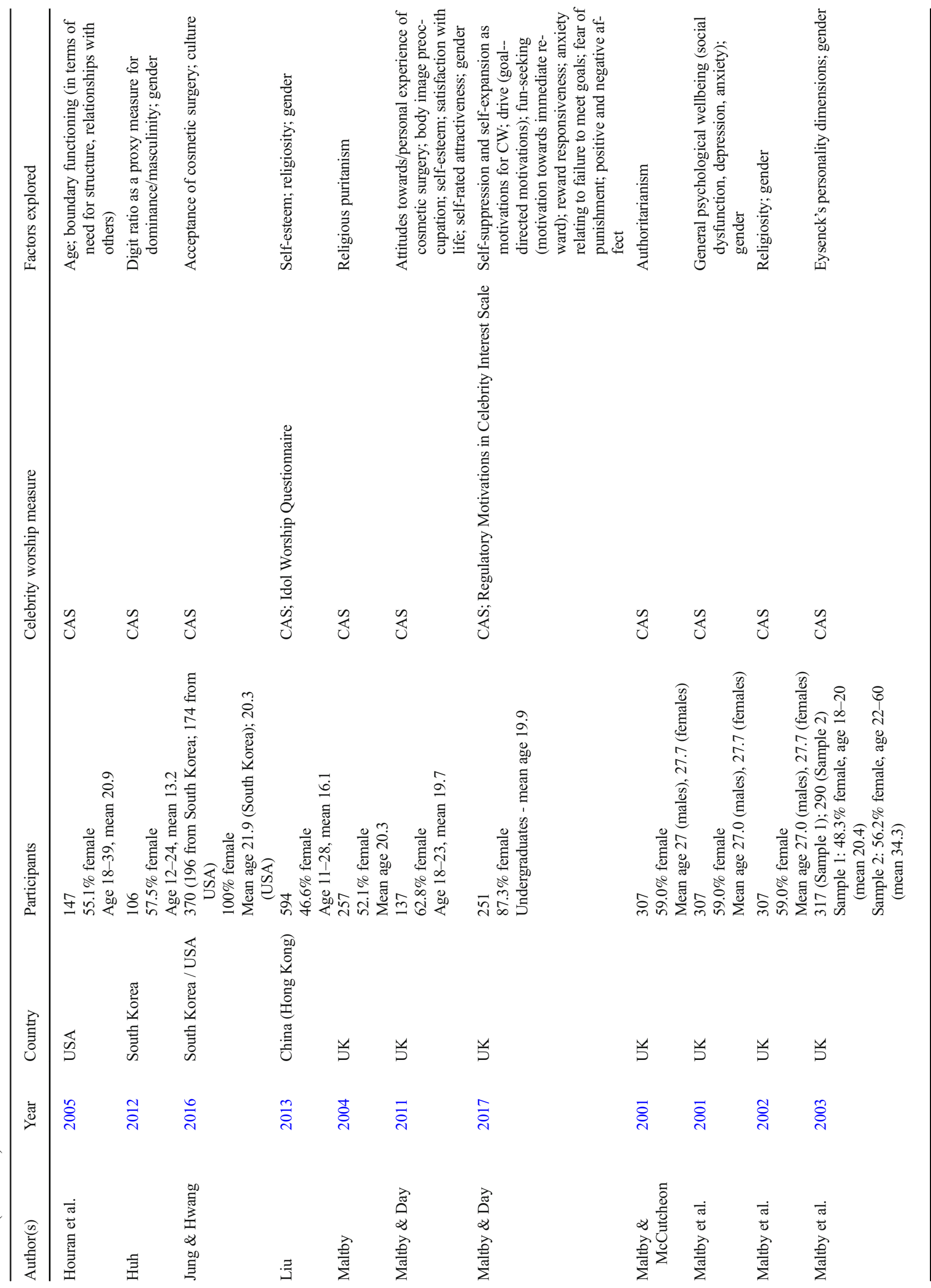




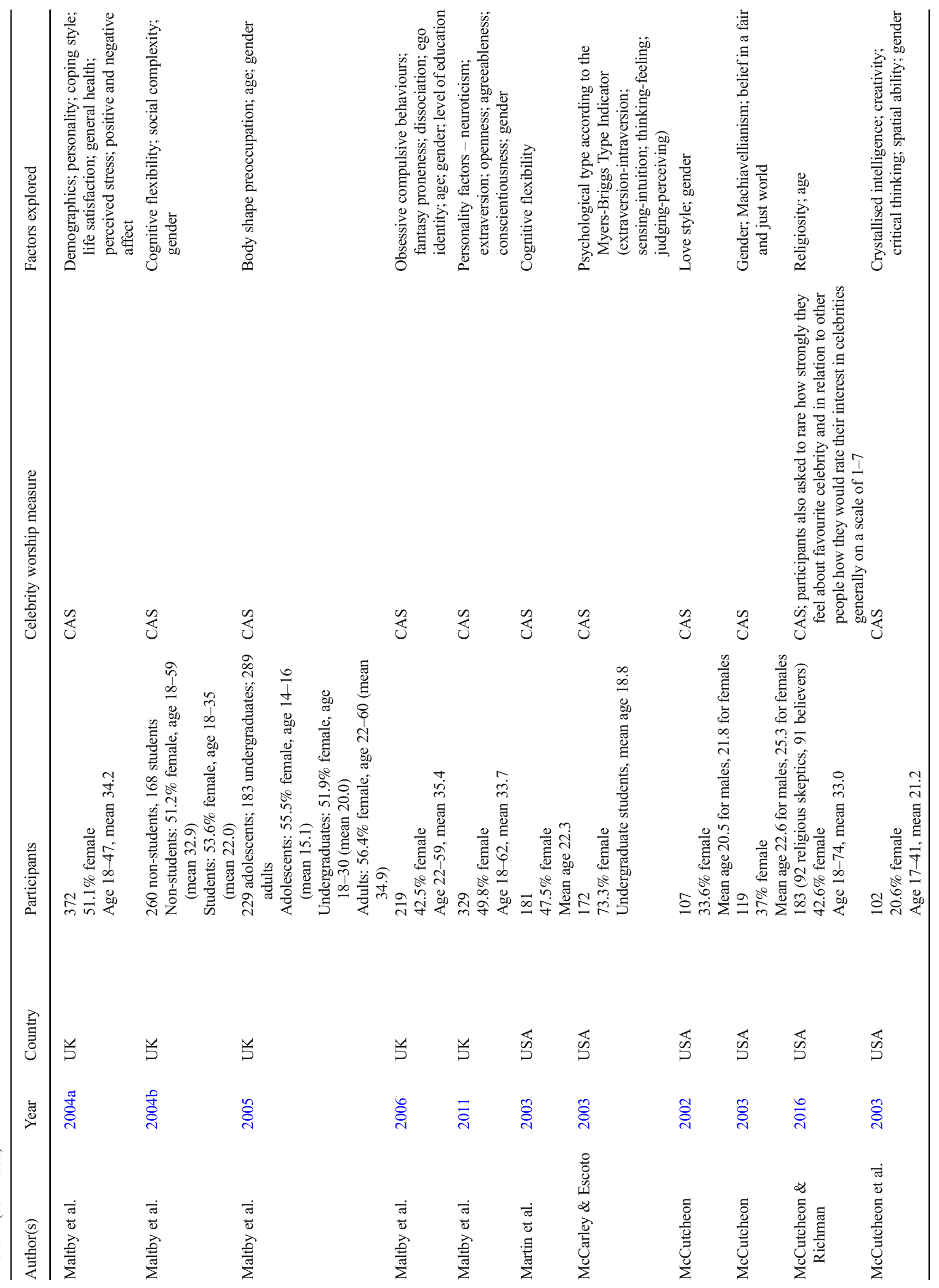




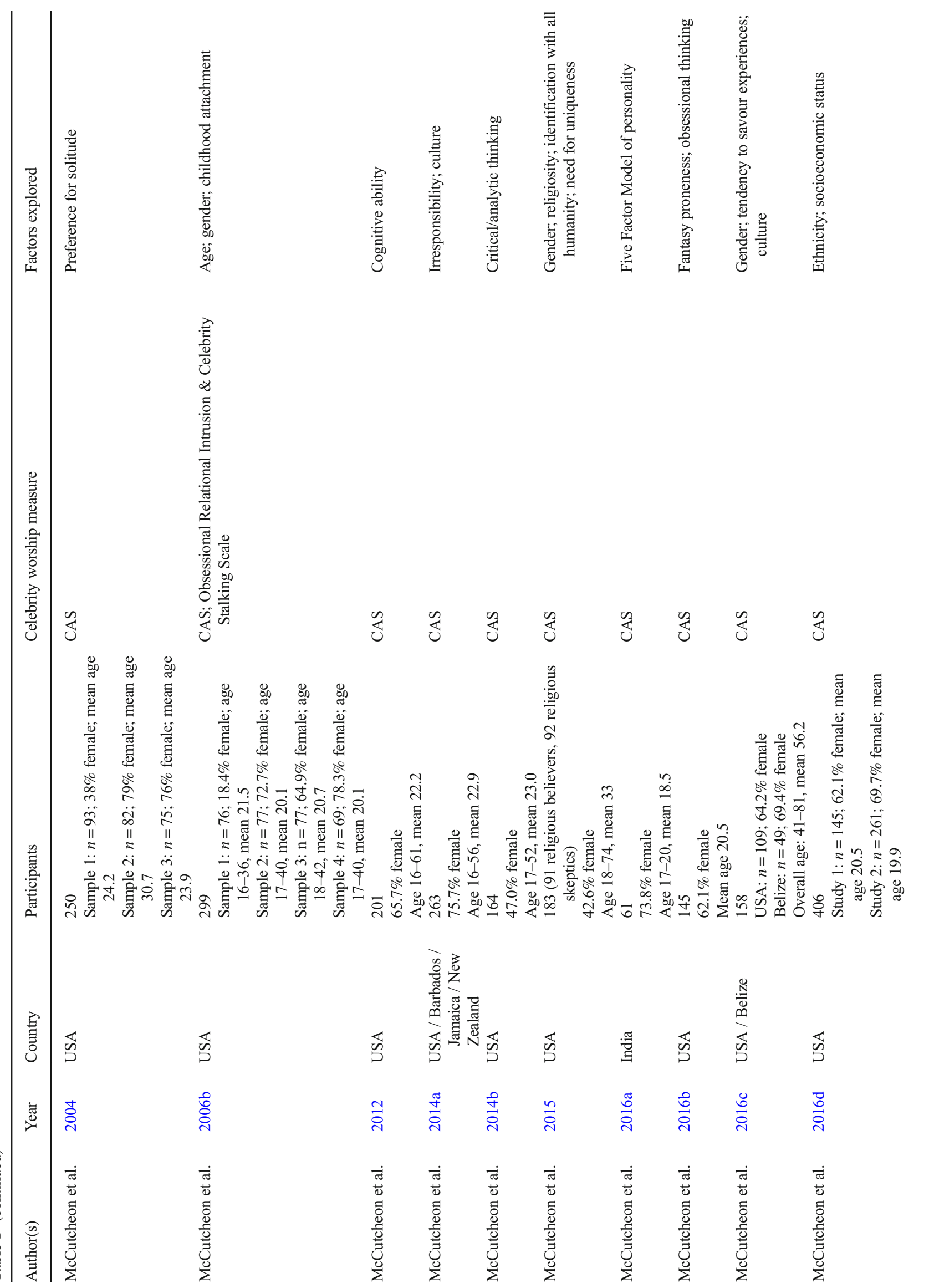




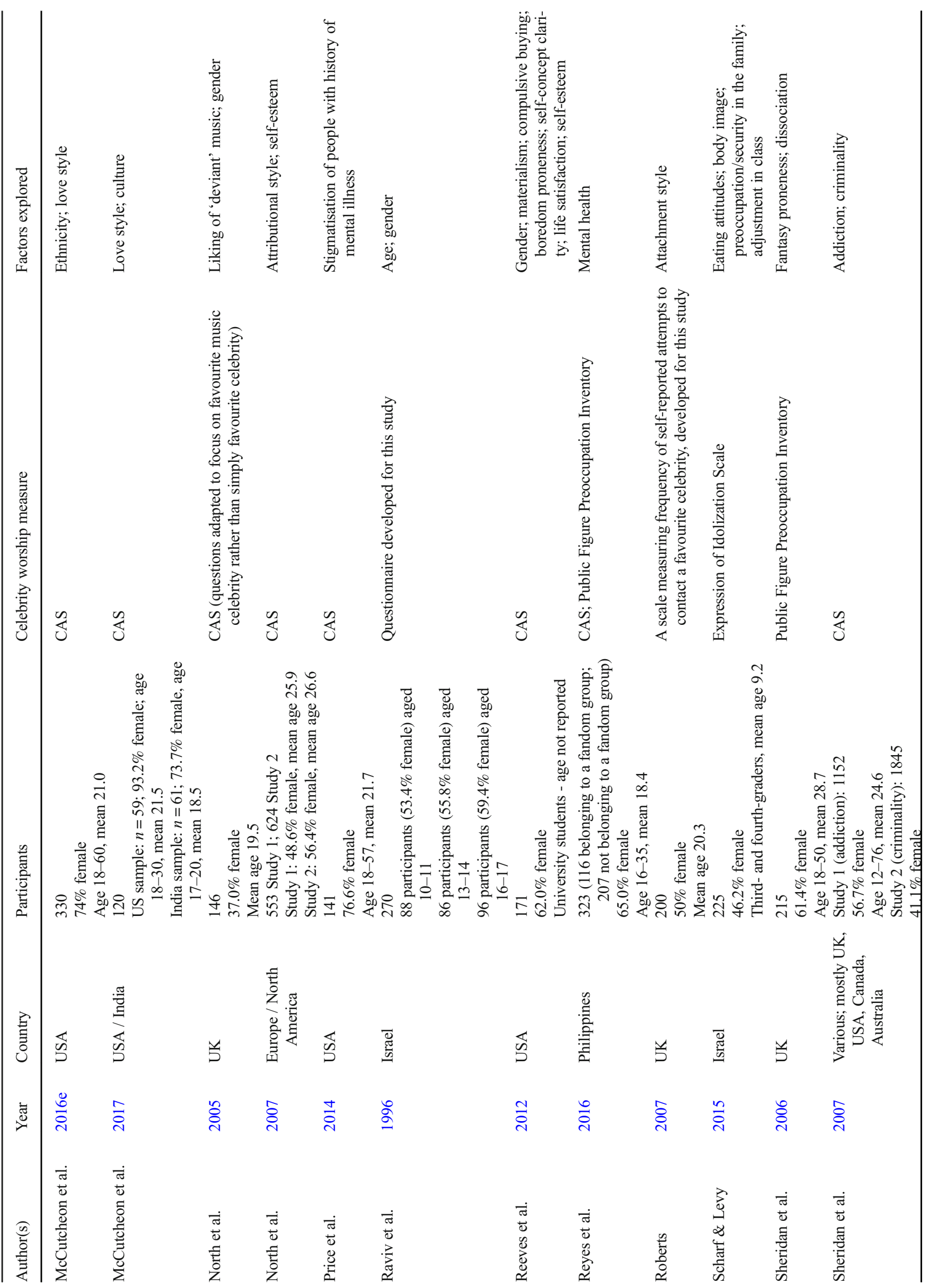




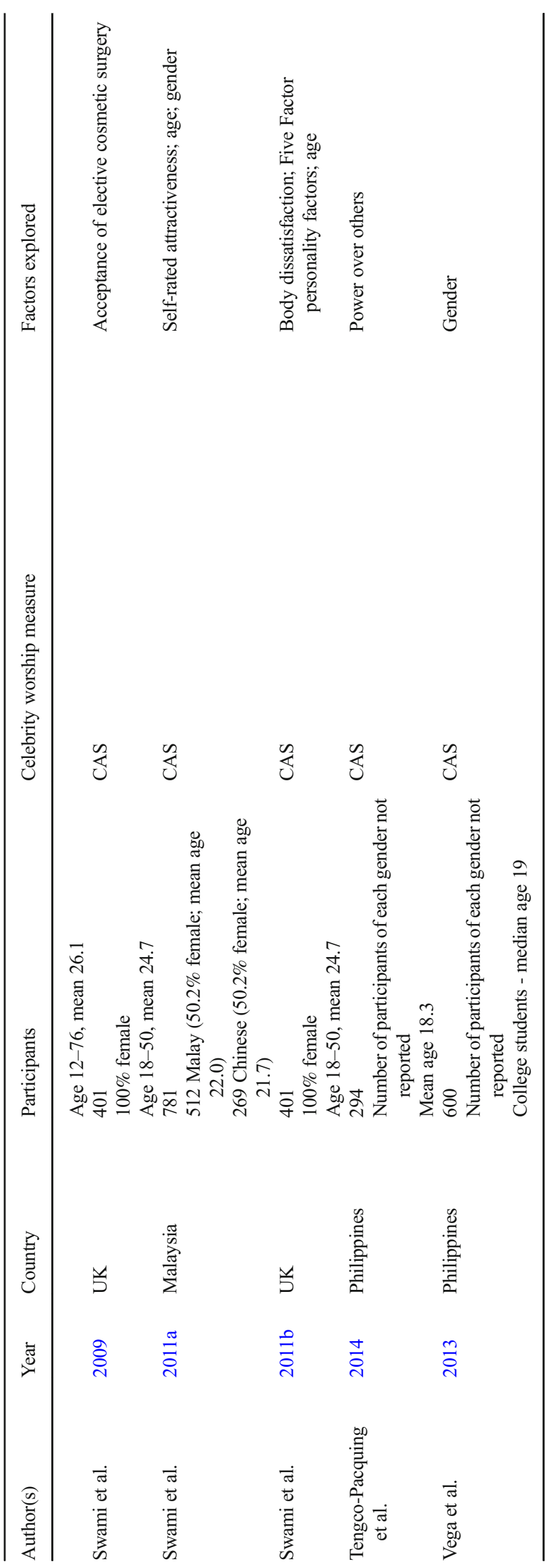




\section{Ethnicity}

McCutcheon et al. (2016d) found that African-Americans had significantly higher total CAS scores, as well as for the entertainment-social and intense-personal subscales, than white participants. African-American participants tended to choose African-American celebrities as their favoured celebrities, while white participants tended to choose white celebrities. McCutcheon et al. (2016e) found that non-white participants scored higher on entertainment-social and intensepersonal CW.

\section{Other}

Maltby et al. (2004a) found no significant relationship between $\mathrm{CW}$ and education, employment or marital status; Maltby et al. (2006) found no association between CW and education. McCutcheon et al. (2016d) found that socioeconomic status was unrelated to CAS scores. However, Cheung and Yue (2012) found that idolisation of celebrities in adolescents was associated with lower parental socioeconomic status.

\section{Personality}

\section{The PEN and Five-Factor Models of Personality}

Several studies explored the relationship between $\mathrm{CW}$ and the dimensions of Eysenck's psychoticism, extraversion and neuroticism (PEN) model of personality (Eysenck and Eysenck 1985). Maltby et al. (2003, 2004a) found significant positive relationships between entertainment-social, intense-personal and borderline-pathological CW and extraversion, neuroticism and psychoticism respectively. Maltby et al. (2011) noted relationships between entertainment-social CW and extraversion and between intense-personal $\mathrm{CW}$ and all facets of neuroticism. McCutcheon et al. (2016a) found correlations between the same dimensions, but these results were not statistically significant.

Three studies also considered CW in relation to the FiveFactor Model of Personality (extraversion, agreeableness, conscientiousness, neuroticism/emotional stability and openness to experience) (Goldberg 1990). McCutcheon et al. (2016a) found that borderline-pathological celebrity worshippers were significantly less conscientious, but Maltby et al. (2011) found neither conscientiousness, openness nor agreeableness were significantly correlated with CAS scores. In the latter study, the 'ideas' subscale of the openness measure was correlated with intense-personal CW for males only. Swami et al. (2011b) found negative correlations between all aspects of $\mathrm{CW}$ and openness, and between intense-personal $\mathrm{CW}$ and agreeableness, conscientiousness, and emotional stability.

\section{Materialism}

A positive correlation was noted between materialistic values and CW (Engle and Kasser 2005; Green et al. 2014); this association appears to be particularly strong for borderlinepathological CW (Green et al. 2014; Reeves et al. 2012). Conversely, Chia and Poo (2009) found that the intensepersonal aspect of $\mathrm{CW}$ was most strongly associated with materialistic values.

\section{Other}

Huh (2012) used 'digit ratio' (the lengths of the second and fourth fingers) as a proxy measure of dominance and masculinity, as these have been significantly associated with digit ratio (Neave et al. 2003). Females with lower digit ratios (associated with greater dominance, aggression and masculinity) were less likely to worship celebrities; no relationship between $\mathrm{CW}$ and digit ratio was found for males.

North et al. (2007) explored CW in relation to attribution theory (Weiner 1986), i.e. the theory that people make attributions according to three dimensions: external-internal (whether events are attributed to factors outside or under the control of the person experiencing them), unstable-stable (the extent to which the cause of an event is attributable to factors that will, or will not, change) and specific-global (whether events are attributed to pervasive factors or isolated to particular aspects of the situation). North et al. (2007) found that entertainment-social $\mathrm{CW}$ was unrelated to attributional style, while intense-personal $\mathrm{CW}$ was associated with a propensity toward stable and global attributions. Borderline-pathological and deleterious imitation $\mathrm{CW}$ were related to external, stable, and global attributions.

McCutcheon et al. (2004) found negative correlations between intense-personal CW and enjoyment of solitude in one sample and productivity during solitude in another sample, suggesting those with strong attachments to their favourite celebrity are somewhat less likely to prefer solitude. Ashe and McCutcheon (2001) found a weak positive correlation between $\mathrm{CW}$ and shyness, which did not reach statistical significance. Reeves et al. (2012) found that CW, particularly borderline-pathological $\mathrm{CW}$, was significantly associated with greater boredom proneness. McCutcheon et al. (2015) found significant positive correlations between the two higher levels of $\mathrm{CW}$ and the need for uniqueness.

Maltby and Day (2017) explored correlations between CAS scores and scores on a biopsychological personality measure. Entertainment-social and intense-personal $\mathrm{CW}$ were both positively associated with reward responsiveness (motivations in anticipation of future rewards); no CAS sub-scales were correlated with drive (goal-directed motivations), funseeking (willingness to approach new situations 
spontaneously), anxiety/inhibition relating to failure to reach goals, or fear/concerns about anticipated punishment. However, in the same study, the authors developed the Regulatory Motivations in Celebrity Interest Scale to explore two self-regulatory motivations for celebrity interest (self-expansion motivated by the desire for personal growth, and self-suppression motivated by suppression of negative goal-related outcomes or negative evaluations from others). They found that both forms of motivation for celebrity interest correlated strongly with all dimensions of the CAS; furthermore, celebrity interest for selfexpansion strongly correlated with both fun-seeking and reward responsiveness, while celebrity interest for selfsuppression strongly correlated with anxiety relating to the failure to meet goals.

McCutcheon et al. (2016c) found positive correlations between entertainment-social $\mathrm{CW}$ and the tendency to savour experiences: in particular, American participants who enjoyed reminiscing about pleasurable events scored significantly higher on entertainment-social CW.

No significant relationships were found between $\mathrm{CW}$ and authoritarianism (Maltby and McCutcheon 2001); the Myers-Briggs Type Indicator dimensions (Briggs-Myers and Briggs 1985) of extraversion vs introversion, sensing vs. intuition, thinking vs. feeling, and judging vs. perceiving (McCarley and Escoto 2003); or Machiavellianism (McCutcheon 2003), although post hoc correlations found that the best 'Machiavellian' item predictive of CW was 'I agree that the most important thing in life is winning', suggesting there may be some relationship between $\mathrm{CW}$ and hyper-competitiveness.

\section{Religiosity}

Maltby et al. (2002) found that CW decreased as religiosity increased. However, the mean correlation coefficient of the religious attitudes scores was low, suggesting that many religious people seemingly ignored the teaching that 'thou shalt worship no other Gods', or did not connect it to worship of celebrities. In a later study Maltby (2004) found a more pronounced significant negative correlation between $\mathrm{CW}$ and religious puritanism. This implies that religious people who show adherence to divine law and church authority tend not to worship celebrities - suggesting that Maltby et al.'s (2002) original claim that religious people fail to connect the 'worship no other Gods' teaching with CW may need revising. Conversely, Liu (2013) found a positive correlation between $\mathrm{CW}$ and religiosity, and two studies found that religious skeptics were less enthusiastic about their favourite celebrities, with religious believers scoring significantly higher on the CAS (McCutcheon and Richman 2016; McCutcheon et al. 2015).
Behavioural and Cognitive-Behavioural Factors

\section{Fantasy Proneness and Dissociation}

Maltby et al. (2006) found that intense-personal and borderline-pathological $\mathrm{CW}$ both correlated positively and significantly with fantasy proneness and dissociation, while entertainment-social $\mathrm{CW}$ was not significantly related to either measure. In a multiple regression, fantasy proneness accounted for unique variance in intense-personal $\mathrm{CW}$, and both fantasy proneness and dissociation accounted for unique variance in borderline-pathological CW. Sheridan et al. (2006) found that preoccupation with a favoured celebrity was significantly related to dissociative experiences and absorption, and McCutcheon et al. (2016b) noted a positive correlation between fantasy proneness and all CAS subscales.

\section{Obsessive Behaviours}

Maltby et al. (2006) found that intense-personal and borderline-pathological $\mathrm{CW}$ both correlated significantly and positively with obsessional-compulsive behaviours, while McCutcheon et al. (2016b) found a positive but nonsignificant correlation between these two types of $\mathrm{CW}$ and obsessional thinking. This study found significant correlations between both intense-personal and borderline-pathological $\mathrm{CW}$ and obsessive, intrusive behaviours towards celebrities, in particular 'persistent pursuit' (willingness to persist in activities that might be an annoyance to the celebrity) and 'threat' (willingness to persist in activities such as letters or phone calls suggesting sexual acts or making obscene comments). Intense-personal $\mathrm{CW}$ remained a predictor of 'persistent pursuit' in a multiple regression.

\section{Other}

McCutcheon et al. (2014a) found that total CAS scores were correlated with measures of irresponsibility (impulsiveness, brief sensation seeking and lack of consideration of future consequences), although only the relationship between $\mathrm{CW}$ and impulsiveness reached statistical significance. Borderline-pathological CW shared a particularly strong relationship with measures of irresponsibility.

Reeves et al. (2012) found that CW was positively related to compulsive buying, with the relationship between borderline-pathological $\mathrm{CW}$ and compulsive buying particularly strong. Sheridan et al. (2007) found that all four aspects of $\mathrm{CW}$ they identified (entertainment-social, intensepersonal, deleterious imitation, and a mixed component including 'infatuation' items as well as other items scattered across the initial subscales) correlated significantly and positively with criminality. 
North et al. (2005) found no significant relationship between $\mathrm{CW}$ towards musicians and listening to 'deviant' music styles.

\section{Feelings about the Self or the World}

\section{Self-Esteem}

North et al. (2007) found that entertainment-social CW was unrelated to self-esteem, but intense-personal CW and the deleterious imitation aspect of $\mathrm{CW}$ were positively related to selfesteem. A positive relationship between intense-personal CW and self-esteem was also found by Ashe et al. (2005), along with a positive relationship between borderline-pathological $\mathrm{CW}$ and all aspects of self-esteem with the exception of 'selfliking'. Perhaps related, Swami et al. (2011a) found that selfrated attractiveness was positively associated with $\mathrm{CW}$, whereas Maltby and Day (2011) found no significant relationship between $\mathrm{CW}$ and self-rated attractiveness.

North et al. (2007) found a negative relationship between borderline-pathological $\mathrm{CW}$ and self-esteem, which was almost - but not quite - significant. A negative relationship between borderline-pathological CW and self-esteem was also noted by Chia and Poo (2009). Cheng (1997) found that members of a fan-club (i.e. those presumably more likely to be 'celebrity worshippers') reported significantly lower selfesteem and significantly higher fear of negative evaluation than those who were not members of a fan-club. Reeves et al. (2012) found that CW was associated with lower selfconcept clarity and lower self-esteem.

Three studies found no significant relationship between CW and self-esteem (Engle and Kasser 2005; Liu 2013; Maltby and Day 2011).

\section{Other}

Ashe et al. (2005) found a significant correlation between total CAS scores and narcissism, but only among UK participants and not a similar sample from the USA which trended in the same direction, but weakly. The UK sample showed significant positive relationships between $\mathrm{CW}$ for entertainmentsocial reasons and the 'authority' aspect of narcissism; CW for intense-personal reasons and all aspects of narcissism; and borderline-pathological $\mathrm{CW}$ and all aspects of narcissism with the exception of 'vanity'. In a multiple regression, exploitativeness accounted for unique variance in intensepersonal CW scores, while both exhibition and selfsufficiency accounted for unique variance in borderlinepathological CW. The US sample showed correlations between intense-personal $\mathrm{CW}$ and the exploitativeness aspect of narcissism, and borderline-pathological CW and both selfsufficiency and vanity. These also accounted for unique variance in a multiple regression analysis; however, when self- esteem was partialed out, the relationship between narcissism and $\mathrm{CW}$ was non-significant.

Cheung and Yue (2003b) found that male adolescents who modelled themselves on celebrities tended to have higher perceived self-efficacy than those who modelled after noncelebrities or those who had no such 'model', while females who modelled themselves on celebrities were lower in selfefficacy than those who did not.

Cheung and Yue (2003a) found that idol worship was related to lower identity achievement. In particular, membership in fan-clubs and years of idol worship emitted significant negative effects on identity achievement. Maltby et al. (2006) found that the two higher levels of $\mathrm{CW}$ were negatively associated with ego identity, though this did not remain a predictor of $\mathrm{CW}$ in multiple regression.

McCutcheon (2003) found that those who believed the world is a fair and just place to live were more likely to worship celebrities.

\section{Cognitive Factors}

Cognitive flexibility was negatively related to intensepersonal CW (Maltby et al. 2004b; Martin et al. 2003) and borderline-pathological dimensions of CW (Martin et al. 2003). Houran et al. (2005) found that all three levels of CW were associated with intolerance of ambiguity, rigidness of thinking reflecting a preference for concreteness in the environment, and need for structure. In the latter study, all three levels of $\mathrm{CW}$ were also associated with thin boundaries concerning delineations between past, present and future, and entertainment-social $\mathrm{CW}$ was associated with openness to child-like feelings.

McCutcheon et al. (2003) found that celebrity worshippers scored significantly lower on measures of crystallised intelligence, creativity, critical thinking and spatial ability. In a multiple regression, however, only creativity (that is, poor creativity indicated by a deficit in the ability to form verbal remote associations) appeared to contribute to the prediction of total CAS scores and to borderline-pathological CW; only spatial ability contributed to prediction of entertainment-social CW; and only critical thinking predicted intense-personal CW. A later study (McCutcheon et al. 2012) found minimal support for the hypothesis that there would be an inverse relationship between CAS scores and measures of cognitive ability. The only correlation significant at the 0.01 level was between intense-personal $\mathrm{CW}$ and advanced reasoning skills; critical thinking, intellectual flexibility and spatial ability appeared to be unrelated. A further study by McCutcheon et al. (2014b) found that scores on a measure of critical thinking correlated negatively with $\mathrm{CW}$; this study also suggested that analytical thinking and logical thinking are not the same, and that there is a relationship between CW and (lack of) ability to reason logically, but not analytically. 


\section{Relationships with Others}

\section{Attachment}

McCutcheon et al. (2006a) found negative (though nonsignificant) correlations between childhood attachment and all aspects of $\mathrm{CW}$; adults who reported insecure attachment as children were also more likely to condone stalking and obsessive behaviours directed towards celebrities. Roberts (2007) found that participants with higher levels of attachment anxiety and lower levels of attachment avoidance were more likely to indulge in approach behaviours towards celebrities. Greenwood and Long (2011) found positive associations between attachment anxiety and imagined intimacy with samegender celebrities, and with imagined intimacy with an opposite-gender celebrity for single participants but not those in relationships; attachment avoidance was not related to imagined intimacy with celebrities of either gender.

Engle and Kasser (2005) found that, for female adolescents, preoccupied attachment to boys was marginally positively correlated with idolisation; secure attachment to boys was related to significantly greater idolisation; avoidant attachment to boys was marginally negatively related to idolisation; and fearful attachment did not appear to be related.

\section{Parental Relationships}

Cheung and Yue (2012) found that celebrity idolisation was predicted by parental absence - when the father or mother were absent, adolescents were more likely to idolise their favoured celebrity and also tended to have older idols, suggesting that a celebrity may serve as a kind of compensatory 'replacement' for a lack of authority figure.

Scharf and Levy (2015) found that celebrity idolisation was associated with levels of preoccupation in the family (e.g. the worry that something could go wrong in the family at any time) and psychological control in the family system (i.e. the extent to which adolescents believed parents would like to have control over them). In a multiple regression, parental psychological control remained a predictor.

Giles and Maltby (2004) found that attachment to parents was negatively associated with $\mathrm{CW}$, while emotional autonomy (the degree to which adolescents perceived themselves as independent from their parents) was positively associated with CW, supporting the idea that attachments to celebrities develop simultaneously with the transference of attachment from parents to peers.

\section{Friendships and Romantic Relationships}

Cheung and Yue (2011) reported a negative relationship between aspects of idol worship and attachment to one's best friend, particularly between 'intimisation' of the idol and attachment to closest friend, suggesting that an 'intimate' parasocial relationship with a celebrity may act as compensation for lacking this sense of intimacy with a best friend. Giles and Maltby (2004) found that entertainment-social CW was associated with high levels of attachment to peers.

Engle and Kasser (2005) found that girls with personal experience of romantic relationships were more likely to idolise (male) celebrities than those with no romantic experience, which contradicted their hypothesis that $\mathrm{CW}$ may be a compensatory function for girls without personal romantic experience.

Greenwood and Long (2011) found that participants not currently in a romantic relationship reported significantly greater imagined intimacy with their preferred oppositegender celebrity than those in a romantic relationship. In this study there was no significant relationship between intimacy in a current romantic relationship and imagined intimacy with a favourite opposite-gender celebrity; however, there was a significant association between intimacy within the context of a same-gender friendship and imagined intimacy with a same-gender media figure.

\section{Romantic Relationship Style}

McCutcheon (2002) found that entertainment-social CW was associated with a 'practical' love style, where one looks for someone who meets the criteria they desire in a partner; borderline-pathological $\mathrm{CW}$ was associated with a 'gameplaying' love style, typified by lack of emotional commitment and interest in having multiple relationships; and CW in general was associated with 'dependent' love, a possessive and jealous style of love often rooted in the fear of being abandoned and uncertainty about the future of relationships. In a smaller sub-sample of participants whose favoured celebrities were likely to be 'fantasy love attractions', significant correlations were found between 'dependent' love and both intense-personal and borderline-pathological $\mathrm{CW}$, and between 'game-playing' love and all three aspects of CW. Some support for these findings has been reported (McCutcheon et al. 2016e, 2017), with participants who scored as 'dependent' lovers tending to also score highly on all three subscales of CAS. In this study, for participants from the USA, 'game-playing' love style was associated with intense-personal CW - although the two appeared unrelated in participants from India. McCutcheon et al. (2016e) noted relationships between intense-personal $\mathrm{CW}$ and both 'practical' and 'dependent' love; entertainment-social CW and 'practical' love; and 'game-playing' love and both intense-personal and borderline-pathological $\mathrm{CW}$, although these did not retain significance in a multiple regression.

McCutcheon et al. (2016e) found that participants with higher scores on all three dimensions of $\mathrm{CW}$ reported higher levels of dominance, submission, separation, and interactional 
reactivity during conflict with a romantic partner; higher anxiety in intimate relationships; and were more likely to endorse soulmate beliefs. Entertainment-social and intense-personal $\mathrm{CW}$ were associated with avoidance during conflict. Borderline-pathological CW was associated with lower tendency to compromise during conflict with romantic partners.

\section{Other}

Positive, but non-significant, correlations were observed between CW and loneliness (Ashe and McCutcheon 2001) and the tendency to envy others (Green et al. 2014). Greenwood and Long (2011) found that 'need to belong' was positively associated with imagined intimacy with oppositegender media figures for single participants but not those in relationships. Maltby et al. (2004b) found a significant negative correlation between intense-personal $\mathrm{CW}$ and social complexity (the extent to which individuals attempt to join and maintain memberships in a number of different groups). McCutcheon et al. (2015) found no correlations between CAS scores and scores on a measure of 'identification with all humanity', i.e. the extent to which one identifies with people all over the world rather than simply in their immediate communities.

Houran et al. (2005) found that poor interpersonal boundaries concerning openness or perceived closeness towards others predicted borderline-pathological $\mathrm{CW}$ : borderlinepathological celebrity worshippers tended to feel disconnected from their social circles despite the desire to form relationships and be open and accepting with others. This type of CW was also associated with thinner boundaries concerning the delineations between the roles of children and adults and the roles individuals play in formal and informal relationships: that is, they blurred the roles placed by society on age groups and individuals within relationships. In the same study, intensepersonal $\mathrm{CW}$ was associated with thin boundaries concerning the roles individuals play in formal and informal relationships: intense-personal celebrity worshippers demonstrated an endorsement of attitudes concerning identity diffusion, i.e. the blurring or merging of identity roles.

Tengco-Pacquing et al. (2014) conducted an experimental study to assess whether a temporary experience of power over others would cause people to value celebrities less. However, there was little difference in CAS scores between the highpower and low-power groups.

\section{Attitudes towards the Body, Eating, and Cosmetic Surgery}

\section{Attitudes towards the Body}

Aruguete et al. (2014) found no relationship between CW and a self-objectification measure designed to assess the extent to which individuals put emphasis on their physical appearance, although CW was positively related to enjoyment of sexualisation, particularly for males.

Scharf and Levy (2015) found that idolisation of celebrities was associated with poorer body image. Maltby et al. (2005) found significant relationships between $\mathrm{CW}$ and body image among female adolescents, although not for students, adults, or adolescent males. For female adolescents there was a significant positive association between intense-personal CW and measures of attention to body shape and body shape preoccupation; while borderline-pathological $\mathrm{CW}$ was also positively correlated with both, only intense-personal CW remained a predictor in multiple regression. Similarly, Swami et al. (2011b) found that body dissatisfaction was significantly positively correlated with scores on the entertainment-social and intense-personal aspects of CW; intense-personal $\mathrm{CW}$ remained a significant predictor in a multiple regression. Maltby and Day (2011) found a significant correlation between intense-personal $\mathrm{CW}$ and body image preoccupation.

\section{Attitudes towards Eating}

Aruguete et al. (2014) found that CW was positively related to disordered eating attitudes. Perhaps surprisingly, this relationship was stronger for men than for women, and was not dependent on whether the favoured celebrities were rated as especially physically attractive - although participants tended to rate the attractiveness of their favourite celebrity as higher than their own. Scharf and Levy (2015) also found that those with high levels of idol worship exhibited more problematic eating behaviours and attitudes, though it is important to note that they believe this relationship is mediated by family ecology and self-esteem.

\section{Attitudes towards Cosmetic Surgery}

Swami et al. (2009) found that individuals who scored highly on CW were significantly more likely to hold positive attitudes about elective cosmetic surgery, with intense-personal $\mathrm{CW}$ emerging as the strongest predictor. Maltby and Day (2011) found that intense-personal CW of a celebrity whose body shape was admired by the participant significantly predicted the incidence of elective cosmetic surgery within an 8month period. Jung and Hwang (2016) reported that for USA participants, CW was positively associated with acceptance of cosmetic surgery and this remained a significant predictor in a multiple regression analysis; however, $\mathrm{CW}$ was not associated with acceptance of cosmetic surgery in a South Korean population in the same study, suggesting there may be a cultural context involved. 


\section{Psychological Wellbeing}

Maltby et al. (2001) found that entertainment-social CW accounted for unique variance in social dysfunction and depressive symptoms, while intense-personal $\mathrm{CW}$ accounted for unique variance in depression and anxiety. Entertainmentsocial CW correlated significantly and positively with anxiety, social dysfunction and depressive symptoms, while both intense-personal and borderline-pathological $\mathrm{CW}$ correlated significantly and positively with anxiety and depressive symptoms. In contrast, Maltby et al. (2004a) found that CW only at the intense-personal level was significantly related to poorer general health (depression, anxiety, somatic symptoms and social dysfunction) and negative affect (stress and low positive affect). The effect of intense-personal $\mathrm{CW}$ on both general mental health and negative affect was mediated by a neurotic coping style comprising denial and disengagement. Reyes et al. (2016) found that CAS scores correlated negatively with scores on a mental health measure, although this correlation was weak. Maltby and Day (2017) found that entertainment-social CW correlated with positive affect while borderline-pathological $\mathrm{CW}$ correlated with negative affect; interestingly intense-personal $\mathrm{CW}$ showed a correlation with negative affect but also a weaker, though still significant, correlation with positive affect. In the same study, celebrity interest for self-expansion reasons correlated positively with positive affect, while celebrity interest for self-suppression reasons correlated positively with negative affect.

Sheridan et al. (2007) found that scores on the CAS positively correlated with a measure of addiction, though after Bonferroni adjustments, addiction scores correlated significantly with only one factor, which was the 'deleterious imitation' aspect of the CAS. Chia and Poo (2009) found that the entertainment-social aspect of CW was positively associated with life satisfaction, and Maltby and Day (2011) found no significant relationship between $\mathrm{CW}$ and satisfaction with life. However two studies (Maltby et al. 2004a; Reeves et al. 2012) found that intensepersonal CW was significantly negatively associated with life satisfaction. Perhaps related to wellbeing, Scharf and Levy (2015) found that children's poor adjustment in class (a measure encompassing sadness, popularity and academic achievements) was associated with higher levels of idolisation.

Despite the apparent associations between $\mathrm{CW}$ and poor mental health, Price et al. (2014) found that those with stronger attachments to celebrities were slightly more likely to stigmatise people with history of mental illness, and there was a significant relationship between intense-personal $\mathrm{CW}$ and stigmatising.

\section{Discussion}

Several studies suggest that $\mathrm{CW}$ is strongest in early adolescence. It appears that people are most likely to worship celebrities at the age when they first begin looking for identification figures other than their parents, and so imagined intimacy with a favoured celebrity may be linked to processes of identity formation and autonomy development (Gleason et al. 2017). Indeed, content analysis of 'fan-mail' by He and Feng (2002) found that letters from young fans tended to emphasise striving to be like their favourite celebrity and wanting to achieve similar goals or possess similar qualities, suggesting celebrities may serve as role models for young people. The decrease in $\mathrm{CW}$ with age may be due to the aspects of $\mathrm{CW}$ associated with identity development becoming less important after adolescence (Swami et al. 2011a). However, Cheung and Yue's (2003a) finding that idol worship is negatively associated with identity achievement is at odds with the suggestion that $\mathrm{CW}$ can help an individual to develop their sense of identity, and worthy of further exploration.

There is some evidence that intense-personal and borderline-pathological $\mathrm{CW}$ may reflect neuroticism and psychoticism respectively, which may provide understanding of why higher levels of CW appear to be related to poorer mental health. There is also evidence of a relationship between materialism and $\mathrm{CW}$, perhaps unsurprisingly given that materialism has been associated with consumption of celebrity magazine and television consumption (Lewallen et al. 2016). There are mixed findings on the relationship between religiosity and $\mathrm{CW}$, with some studies suggesting religious people are less likely to worship celebrities and others suggesting skeptics are less likely to. It has been hypothesised that the function of $\mathrm{CW}$ is to address the latent need for a religious experience (Alexander 2010) and it would be interesting to explore whether a loss of religious belief may be associated with $\mathrm{CW}$; that is, perhaps those who were previously religious but experienced a loss of faith may turn to a favoured celebrity to fill this gap. It would also be useful for researchers into CW to distinguish between intrinsic and extrinsic religiosity in order to help clarify the relationship between $\mathrm{CW}$ and religion. According to Allport and Ross (1967), a person with intrinsic religious orientation believes wholly in their religion and lives their life according to the ways their religion preachers that they should, while for those with extrinsic religious orientation, religion is more self-serving and is used for achieving non-religious goals such as distraction, security and self-justification. It may be the case that the relationship between $\mathrm{CW}$ and religion is determined by the motivations behind religiosity and whether its orientation is intrinsic or extrinsic. Future research should more thoroughly explore the relationship between $\mathrm{CW}$ and experiences with religion.

Fantasy proneness appears to be associated with the higher levels of CW in particular. This relationship may be reflective of a need for escapism and could tie in with the concept of 'transportation' (Brown 2015; Green 2004; Green et al. 2004). Transportation refers to an individual becoming completely immersed and involved in a narrative world and with the 
characters in that world, metaphorically being transported to a different place where they can imagine themselves in that world. Though typically this refers to fictional characters and worlds, it can also refer to the worlds of real people. It may be interesting to consider whether $\mathrm{CW}$ is related to the tendency to be 'transported' during media consumption.

We would expect higher levels of $\mathrm{CW}$ to be associated with lower self-esteem, due to the theory that $\mathrm{CW}$ is linked to a deficit in self-concept or identity and acts as a compensation for an 'empty self' (Cushman 1990; McCutcheon et al. 2002; Reeves et al. 2012). However, several studies demonstrate a positive relationship between $\mathrm{CW}$ and self-esteem. As these studies are correlational, we cannot ascertain whether $\mathrm{CW}$ actually improves self-esteem, but it would be interesting to explore this as it would add a parasocial dimension to existing theories of the relationship between social identity and selfesteem (e.g. Tajfel and Turner 1986). Indeed there is some research to suggest that identification with a celebrity similar to one's ideal self can enhance self-esteem; by assimilating favourite celebrities to the self, the discrepancy between the actual and ideal selves can be reduced (Derrick et al. 2008). There is some evidence that narcissism may be associated with $\mathrm{CW}$, perhaps related to fans seeing themselves as an extension of their favoured celebrity and therefore worthy of the same adoration. This relates to Alexander's (2010) suggestion that engagement with celebrities can be understood as a process wherein the celebrity becomes part of the internal self. It is also possible that as narcissists are likely to have difficulty maintaining real relationships (Campbell and Foster 2002), parasocial relationships with celebrities may fill this gap for them.

Cognitive flexibility appears to be negatively related to intense-personal $\mathrm{CW}$ in particular. People engaging in this type of CW appear more likely to be inflexible or 'locked into' their views and lack awareness or the ability to cope with alternative options. Maltby et al. (2004b) relate this to intense-personal celebrity worshippers being unable to deal with the real world and only seeing value in their favoured celebrity and little else.

CW also appears to be associated with poor-quality intimate relationships and difficulty coping with conflicts. Arguably, the association between $\mathrm{CW}$ and poor relationships may be due to celebrity attachment acting as a compensation to make up for what is lacking in real-life relationships. McCutcheon (2002) suggests that 'dependent' lovers, driven by lack of confidence and need for love, may develop attachments to celebrities as a backup plan, providing a sense of security in the case of a real-life relationship break-up. This is supported by Stever (2011a) who notes that parasocial attachments are often sought during critical life transitions, such as the loss of relationships, and argues that attachment to celebrities is a way of re-engaging with the world of relationships in a safe, non-threatening way.
Karniol (2001) found that young girls who had, or wanted, a boyfriend tended to idolise non-feminine celebrities, whereas girls who did not want a boyfriend tended to choose feminine idols, suggesting that celebrities might provide a safe target of romantic love for adolescents.

It is not new to suggest that the media influences body image and eating attitudes (Cusomano and Thompson 1997; Harrison and Cantor 1997), but the papers presented here suggest that $\mathrm{CW}$ may be a specific aspect of media influence worth more attention. Those who maintain a parasocial relationship with a favoured celebrity also appear more likely to endorse cosmetic surgery, perhaps due to a combination of internalisation of media beauty standards and desire to be like one's favoured celebrity.

Finally, there is some evidence that $\mathrm{CW}$ is related to poorer psychological wellbeing (e.g. depression, anxiety) although it is important to note that due to the correlational nature of the research directionality cannot be assumed. This will be discussed further in the limitations section of this paper.

Overall, CW as a 'substitute', or compensation for something lacking, appears to be a recurring theme. There is much evidence to suggest that people lacking in internal resources (such as self-concept or self-esteem) may use CW as a way of seeking external stimulation and gratification in an attempt to compensate for these deficits (Reeves et al. 2012). This is supported by He and Feng's (2002) analysis of fan-mail which found that whatever attributes the letter-writers lacked, or felt were insufficient, in their own lives tended to be the things they particularly liked about their idol.

\section{Limitations}

\section{Limitations of the Review}

A small number of studies were included which did not use a specific measure of $\mathrm{CW}$ but included particular behaviours associated with being a serious fan (e.g. being a member of a fan-club). It is likely that such behaviours are indicative of $\mathrm{CW}$; research has found that 'fan-club' or organised fandom group members score significantly higher on the CAS than non-members (Liu 2013; Reyes et al. 2016). However, Stever (2011b) administered the CAS to a subset of individuals who exhibited 'fan' behaviour (e.g. writing fan letters, attending events to meet celebrities, joining fan-clubs, or having memorabilia collections focusing on one celebrity) and found the majority had low scores, suggesting one can be a serious fan without being a 'celebrity worshipper'. If CW and 'being a serious fan' are conceptually different constructs, it is arguable whether this review should have focused solely on papers with a direct $\mathrm{CW}$ measure.

The decision to limit the review to English-language studies published in journals means that papers published in different languages were missed and there is the potential for 
publication bias. Future reviews may consider translating foreign-language papers and searching grey literature.

The screening and analysis of papers were all carried out by one author. It may have been useful to have a second researcher involved in these stages to ensure that no relevant papers were missed and to provide consensus for the interpretation of the results.

\section{Limitations of the Literature}

The research on CW relies overwhelmingly on cross-sectional, correlational data, simply exploring associations between $\mathrm{CW}$ and various psychosocial characteristics. While useful in itself, it is impossible to ascertain the directionality of these relationships. For example, it may be the case that $\mathrm{CW}$ destabilises fans psychologically, but it may also be that people with mental health difficulties are more likely to become attached to celebrities in the first place, possibly as a distraction from negative feelings. Similarly, if poor relationships are associated with $\mathrm{CW}$, it may be the case that $\mathrm{CW}$ occurs first and this absorption interferes with the ability to maintain other relationships, but it is equally likely that those who have difficulty forming or maintaining secure relationships seek parasocial relationships with celebrities as less threatening substitutes. Despite the inability to ascertain directionality from correlational research, Hyman and Sierra (2010) use the literature to suggest that high-level CW can have damaging effects on mental health, hinder interpersonal relationships, and reduce cognitive and communicative flexibility. It is arguable in these cases whether $\mathrm{CW}$ is the cause or effect, and the correlational data available should not be used to assume directionality in these associations.

\section{Directions for Future Research}

There are several potential new avenues for future research emerging from this review. Firstly, prospective or longitudinal studies are needed to explore how $\mathrm{CW}$ and the factors associated with it change over time. This may provide a better understanding of the directionality between $\mathrm{CW}$ and associated factors. Secondly, it is notable that there is a lack of qualitative research in the area of $\mathrm{CW}$ generally. Future researchers should consider using qualitative methodology to allow the fans themselves a 'voice' in the research and to explore the fans' perceptions of CW. Thirdly, it would be useful for parametric studies to be carried out in order to ascertain what percentage of the population could be classified as 'celebrity worshippers' - in particular, what percentage could be classed as demonstrating the higher levels of CW (intense-personal and borderline-pathological).

Additionally, more theoretical research on $\mathrm{CW}$ is needed. While researchers have explored various factors associated with $\mathrm{CW}$ in depth, as demonstrated in this review, the majority of the studies carried out to date do not adequately discuss the implications of McCutcheon et al.'s (2002) absorptionaddiction model of $\mathrm{CW}$, for example. It may be useful to consider this in relation to self-determination theory (Deci and Ryan 2002). This theory differentiates between intrinsic motivation (internal drives to behave in certain ways, due to interests or value) and extrinsic motivation (the drive to behave in certain ways which comes from external sources, such as the desire for success, popularity or rewards). Both intrinsic and extrinsic motivations for behaviour drive people to meet the three innate psychological needs which self-determination theory suggests are needed in order to function optimally: competence (the need to develop mastery over important skills), relatedness (the need for a sense of belonging) and autonomy (the need to feel in control of one's life). Much of the research discussed in this review suggests that celebrity worshippers try to gain satisfaction through extrinsic means (i.e. worshipping celebrities) rather than pursuing the basic intrinsic goals of competence, relatedness and autonomy. Further theoretical research could provide a deeper understanding of $\mathrm{CW}$.

Further research is also needed into the psychometric properties of the CAS. This could include relationships between the CAS and similar scales developed to measure aspects of fan behaviours and attitudes towards celebrities. This research is necessary in order to fully explore the constructs being measured by the CAS and distinguish them from related constructs such as fanship - for example, Stever (2011b) suggests that being a fan and being a celebrity worshipper are not synonymous, pointing out that even those who could be considered 'serious fans' who joined fan clubs or wrote letters to celebrities do not necessarily score highly on the CAS. A more in-depth exploration of the specific constructs being measured by the CAS and how they differ from fan behaviours in general would provide better understanding of what $\mathrm{CW}$ is and the relationship between $\mathrm{CW}$ and being a fan.

It is important to understand how CW may impact on other areas of a person's life: while research has considered this in terms of social and emotional effects, there is yet to be research on the potential financial impact of CW. It may be the case that celebrity worshippers spend more money than nonworshippers - for example, on concert tickets, films, memorabilia related to the favoured celebrity or products endorsed by them. It would therefore be useful to explore the relationship between $\mathrm{CW}$ and consumer behavior in more detail.

As discussed, McCutcheon et al. (2016d, 2016e) found that non-white participants tended to be more likely to engage in $\mathrm{CW}$. The authors proposed that escapism into the world of celebrities may help people escape the potentially unpleasant reality of being a minority group, and that minority groups may derive a sense of self-esteem from strong identification with a celebrity belonging to the same group. It would be useful to explore whether there is a similar association in other 
minority groups, such as the lesbian, gay, bisexual and transgender communities. There is some evidence to suggest that homosexual or bisexual individuals are more likely to select homosexual/bisexual media personae as their favourites, particularly those reporting loneliness in their own lives (Bond 2018), and that attachment to such celebrities can be a meaningful form of socialisation for this group.

The fan-celebrity relationship is generally viewed as onesided. However, fans often seek the reciprocity of real interactions with their favoured celebrities (Ferris 2001; Roberts 2007); in recent years, the internet has dramatically altered the fan-celebrity relationship, allowing a more intimate connection between the two and introducing a new dynamic to this relationship (Giles 2017; Stever 2011b). The proliferation of social media sites, which many celebrities use to communicate to and interact with their fans, provides a direct, immediate connection between celebrity and fan which may be meaningful for both parties (Stever and Lawson 2013). Given the relative ease of connecting with celebrities in the age of social media, fans can have repeated interactions with their favourite celebrities and could begin to see them as important parts of their social network. The effect of this has not been fully explored, although there is some evidence that dependency on parasocial relationships with celebrities on social media is associated with poor interpersonal trust (Baek et al. 2013). It would be useful to consider how this change in the fan-celebrity dynamic impacts upon $\mathrm{CW}$ and also on fan wellbeing.

There are also questions as to whether even those who would be classified as extreme celebrity worshippers, according to the CAS, should be classed as pathological and whether $\mathrm{CW}$ actually does have a negative impact on their lives. Much of the research discussed in this review explains $\mathrm{CW}$ negatively, often in terms of deficits in relationships or self-concept, and it appears that the attitude of the general public towards $\mathrm{CW}$ is negative: for example, McCutcheon and Maltby (2002) asked participants to select adjectives which they believed described a celebrity worshipper. The adjectives which emerged most frequently were negative: 'foolish', 'irresponsible', 'submissive', 'persistent' and 'dishonest'. The negative attributions of celebrity worshippers may be due in part to media stories about the negative side of celebrity fixation such as stalking and harassment (Meloy et al. 2008; Mullen et al. 2009); more benign forms of CW do not make headlines and it is perhaps understandable that non-worshippers would hold negative views. However, those who were classed as celebrity worshippers themselves in the McCutcheon and Maltby (2002) study tended to view worshippers more favourably and rated them higher on both social and intelligence-related attributes than non-worshippers. So, despite the general view of non-worshippers that $\mathrm{CW}$ is a negative concept, it appears that those who experience $\mathrm{CW}$ have more favourable attitudes towards it and those who engage in it. It is also apparent that the impact of $\mathrm{CW}$ on the lives of the fans has not been thoroughly explored. It may be useful to develop a scale of measurement for this, for example asking participants to rate how their relationship with their favoured celebrity makes them feel and the extent to which their favoured celebrity has had a positive or negative impact on their lives. This may provide insights into whether CW is perceived by celebrity worshippers themselves as positive or negative.

Most of the research exploring the positive side of being a fan has focused mainly on 'fandoms' and connections with other fans, suggesting this can have a positive impact in terms of identification, belongingness, and psychological benefits (Gabriel and Young 2011; Obst et al. 2002). Less attention has been paid to the potential positive associations of $\mathrm{CW}$. There is however some evidence that parasocial relationships can be positive: Stever (2011a) argues that they can help people deal with loss by allowing them to reconnect with certain emotions, while Cohen (2001) suggests parasocial relationships can help develop empathy. He (2006) suggests that idol worship in adolescents is positive and healthy, with young people drawing lessons and inspiration from celebrities, while Boon and Lomore (2001) report that CW can also be a motivator for achieving goals in older fans.

Sansone and Sansone (2014) suggest that CW should be viewed as a continuum, with 'normal' admiration at one end of the scale and psychopathological obsession at the other. Taking McCutcheon et al.'s (2002) absorption-addiction model of $\mathrm{CW}$, then, we would assume that entertainment-social $\mathrm{CW}$ is at one end of the continuum, with intense-personal $\mathrm{CW}$ towards the other end of the continuum and borderlinepathological at the most extreme end. However, it may not be the case that high scores on the more intense levels of $\mathrm{CW}$ are necessarily problematic: Ang and Chan (2016) interviewed teenagers who scored at or above the midpoint of the three CAS sub-scales to explore the impact of $\mathrm{CW}$ on their lives. Their participants described only positive effects, reporting that $\mathrm{CW}$ provided inspiration, helped develop self-determination, enhanced personal and social relationships, helped modulate negative emotions, exposed them to new cultures, introduced new friends to their lives and helped overcome shyness. This suggests that $\mathrm{CW}$ can be positive even for those scoring highly on the more problematic dimensions of the CAS; it would be interesting to explore whether similar positive outcomes would also be reported by adults. If it is not the level of $\mathrm{CW}$ which determines whether $\mathrm{CW}$ has a negative impact, it may well be the case that it is the motivation behind $\mathrm{CW}$ which is important. Perhaps fans whose interest in their favourite celebrity stems from self-suppression are those most likely to have their wellbeing negatively impacted. It is hoped that the new Regulatory Motivations in Celebrity Interest Scale (Maltby and Day 2017) will become more widely used in the context of celebrity interest research, providing more insights into the motivations of attachment to celebrities. 
Future research asking fans about the impact of $\mathrm{CW}$ on their lives is also important in ascertaining whether there might be a positive side to $\mathrm{CW}$, and qualitative research in particular would allow for a better understanding of $\mathrm{CW}$ in terms of how celebrity worshippers themselves perceive the experience.

Acknowledgements The author gratefully acknowledges Sonny Patel for his feedback on an early draft of this manuscript. Thanks must also go to Nancy McCarley and Lynn McCutcheon for providing full-text copies of three articles which were unavailable online.

\section{Compliance with Ethical Standards}

Conflict of Interest The author declares there is no conflict of interest for this paper.

Open Access This article is distributed under the terms of the Creative Commons Attribution 4.0 International License (http:// creativecommons.org/licenses/by/4.0/), which permits unrestricted use, distribution, and reproduction in any medium, provided you give appropriate credit to the original author(s) and the source, provide a link to the Creative Commons license, and indicate if changes were made.

\section{References}

Alexander, J. C. (2010). The celebrity-icon. Cultural Sociology, 4(3), 323-336.

Allport, G. W., \& Ross, J. M. (1967). Personal religious orientation and prejudice. Journal of Personality and Social Psychology, 5, 432-443.

Ang, C.-S., \& Chan, N.-N. (2016). Adolescents' views on celebrity worship: A qualitative study. Current Psychology, 37, 139-148. https:// doi.org/10.1007/s12144-016-9497-0, .

Aruguete, M., Griffith, J., Edman, J., Green, T., \& McCutcheon, L. (2014). Body image and celebrity worship. Implicit Religion, 17(2), 223-234.

Ashe, D. D., \& McCutcheon, L. E. (2001). Shyness, loneliness, and attitude toward celebrities. Current Research in Social Psychology, 6(9), 124-132.

Ashe, D. D., Maltby, J., \& McCutcheon, L. E. (2005). Are celebrityworshippers more prone to narcissism? A brief report. North American Journal of Psychology, 7(2), 239-246.

Austin, E. W., Van de Vord, R., Pinkleton, B. E., \& Epstein, E. (2008). Celebrity endorsements and their potential to motivate young voters. Celebrity Studies, 11(4), 420-436.

Baek, Y. M., Bae, Y., \& Jang, H. (2013). Social and parasocial relationships on social network sites and their differential relationships with users' psychological well-being. Cyberpsychology, Behavior, and Social Networking, 16(7), 512-517.

Basil, M. D. (1996). Identification as a mediator of celebrity effects. Journal of Broadcasting and Electronic Media, 40, 478-495.

Bond, B. J. (2018). Parasocial relationships with media personae: Why they matter and how they differ among heterosexual, lesbian, gay, and bisexual adolescents. Media Psychology, 21, 457-485. https:// doi.org/10.1080/15213269.2017.1416295.

Boon, S. D., \& Lomore, C. D. (2001). Admirer-celebrity relationships among young adults: Explaining perceptions of celebrity influence on identity. Human Communication Research, 27(3), 432-465.
Branch, S. E., Wilson, K. M., \& Agnew, C. R. (2013). Committed to Oprah, Homer, or house: Using the investment model to understand parasocial relationships. Psychology of Popular Media Culture, 2(2), 96-109.

Braun, V., \& Clarke, V. (2006). Using thematic analysis in psychology. Qualitative Research in Psychology, 3(2), 77-101.

Briggs-Myers, I., \& Briggs, K. C. (1985). Myers-Briggs type Indicator (MBTI). Palo Alto: Consulting Psychologists Press.

Brown, W. J. (2015). Examining four processes of audience involvement with media personae: Transportation, parasocial interaction, identification, and worship. Communication Theory, 25, 259-283.

Brown, W. J., \& Basil, M. D. (1995). Media celebrities and public health: Responses to "magic" Johnson's HIV disclosure and its impact on AIDS risk and high-risk behaviours. Health Communication, 7(4), 345-370.

Brown, W. J., \& de Matviuk, M. A. (2010). Sports celebrities and public health: Diego Maradona's influence on drug use prevention. Journal of Health Communication, 15(4), 358-373.

Campbell, W. K., \& Foster, C. A. (2002). Narcissism and commitment in romantic relationships: An investment model analysis. Personality and Social Psychology Bulletin, 28(4), 484-495.

Casey, G. M., Morris, B., Burnell, M., Parberry, A., Singh, N., \& Rosenthal, A. N. (2013). Celebrities and screening: A measurable impact on high-grade cervical neoplasia diagnosis from the 'jade goody effect' in the UK. British Journal of Cancer, 109(5), 11921197.

Chapman, S., McLeod, K., Wakefield, M., \& Holding, S. (2005). Impact of news of celebrity illness on breast cancer screening: Kylie Minogue's breast cancer diagnosis. Medical Journal of Australia, 183(5), 247-250.

Cheng, S. T. (1997). Psychological determinants of idolatry in adolescents. Adolescence, 32(127), 687-692.

Cheung, C.-K., \& Yue, X. D. (2003a). Identity achievement and idol worship among teenagers in Hong Kong. International Journal of Adolescence and Youth, 11(1), 1-26.

Cheung, C.-K., \& Yue, X. D. (2003b). Adolescent modelling after luminary and star idols and development of self-efficacy. International Journal of Adolescence and Youth, 11(3), 251-267.

Cheung, C.-K., \& Yue, X. D. (2011). Pentangular dimensions of Chinese adolescents' idol worship. International Journal of Adolescence and Youth, 16(3), 225-244.

Cheung, C.-K., \& Yue, X. D. (2012). Idol worship as compensation for parental absence. International Journal of Adolescence and Youth, 17(1), 35-46.

Chia, S. C., \& Poo, Y. L. (2009). Media, celebrities, and fans: An examination of adolescents' media usage and involvement with entertainment celebrities. Journalism \& Mass Communication Quarterly, 86(1), 23-44.

Chung, S., \& Cho, H. (2017). Fostering parasocial relationships with celebrities on social media: Implications for celebrity endorsement. Psychology \& Marketing, 34(4), 481-495.

Cohen, J. (2001). Defining identification: A theoretical look at the identification of audiences with media characters. Mass Communication and Society, 4(3), 245-264.

Cushman, P. (1990). Why the self is empty. Toward a historically situated psychology. The American Psychologist, 45(5), 599-611.

Cusomano, D. L., \& Thompson, J. K. (1997). Body image and body shape ideals in magazines: Exposure, awareness and internalization. Sex Roles, 37(9-10), 701-721.

Deci, E. L., \& Ryan, R. M. (2002). Handbook of self-determination research. Rochester: University of Rochester Press.

Derrick, J. L., Gabriel, S., \& Tippin, B. (2008). Parasocial relationships and self-discrepancies: Faux relationships have benefits for low selfesteem individuals. Personal Relationships, 15, 261-280.

Engle, Y., \& Kasser, T. (2005). Why do adolescent girls idolize male celebrities? Journal of Adolescent Research, 20(2), 263-283. 
Eysenck, H. J., \& Eysenck, M. W. (1985). Personality and individual differences: A natural science approach. New York: Plenum.

Ferris, K. O. (2001). Through a glass, darkly: The dynamics of fancelebrity encounters. Symbolic Interaction, 24(1), 25-47.

Fraley, R. F., \& Davis, K. E. (1997). Attachment formation and transfer in young adults' close friendships and romantic relationships. Personal Relationships, 4, 131-144.

Gabriel, S., \& Young, A. F. (2011). Becoming a vampire without being bitten: The narrative collective-assimilation hypothesis. Psychological Science, 22, 990-994.

Giles, D. (2000). Illusions of immortality: A psychology of fame and celebrity. New York: St Martin's Press.

Giles, D. (2002). Parasocial interaction: A review of the literature and a model for future research. Media Psychology, 4, 279-305.

Giles, D. C. (2017). How do fan and celebrity identities become established on twitter? A study of 'social media natives' and their followers. Celebrity Studies, 8(3), 445-460.

Giles, D. C., \& Maltby, J. (2004). The role of media figures in adolescent development: Relations between autonomy, attachment, and interest in celebrities. Personality and Individual Differences, 36, 813-822.

Giles, D., \& Maltby, J. (2006). Praying at the altar of the stars. The Psychologist, 19(2), 82-85.

Gleason, T. R., Theran, S. A., \& Newberg, E. M. (2017). Parasocial interactions and relationships in early adolescence. Frontiers in Psychology, 8, 255

Goldberg, L. R. (1990). An alternative "description of personality": The big-five factor structure. Journal of Personality and Social Psychology, 59, 1216-1229.

Green, M. C. (2004). Transportation into narrative worlds: The role of prior knowledge and perceived realism. Discourse Processes, 38, 247-266.

Green, M. C., Brock, T. C., \& Kaufman, G. F. (2004). Understanding media enjoyment: The role of transportation into narrative worlds. Communication Theory, 14, 311-327.

Green, T., Griffith, J., Aruguete, M. S., Edman, J., \& McCutcheon, L. E. (2014). Materialism and the tendency to worship celebrities. North American Journal of Psychology, 16(1), 33-42.

Greene, A. L., \& Adams-Price. (1990). Adolescents' secondary attachments to celebrity figures. Sex Roles, 23(7,8), 335-347.

Greenwood, D. N., \& Long, C. R. (2011). Attachment, belongingness needs, and relationship status predict imagined intimacy with media figures. Communication Research, 38(2), 278-297.

Greenwood, D. N., Pietromonaco, P. R., \& Long, C. R. (2008). Young women's attachment style and interpersonal engagement with female TV stars. Journal of Social and Personal Relationships, 25(3), 387-407.

Griffith, J., Aruguete, M., Edman, J., Green, T., \& McCutcheon, L. (2013). The temporal stability of the tendency to worship celebrities. SAGE Open, 3(2), 1-5.

Hackley, C., \& Hackley, R. A. (2016). The iconicity of celebrity and the spiritual impulse. Consumption Markets \& Culture, 19(3), 269-274.

Harrison, K., \& Cantor, J. (1997). The relationship between media consumption and eating disorders. Journal of Communications, 47(1), $40-67$.

He, X. Z. (2006). Survey report on idol worship among children and young people. Chinese Education \& Society, 39(1), 84-103.

He, Y. Z., \& Feng, X. T. (2002). Idol worship among the youth: A sociological analysis of 207 letters from Zhao Wei fans. Chinese Education \& Society, 35(6), 81-94.

Hollander, P. (2010). Why the celebrity cult? Society, 47(5), 388-391.

Horton, D., \& Wohl, R. R. (1956). Mass communication and Para-social interaction. Psychiatry: Journal for the Study of Interpersonal Processes, 19, 215-229.

Houran, J., Navik, S., \& Zerrusen, K. (2005). Boundary functioning in celebrity worshippers. Personality and Individual Differences, $38(1), 237-248$.
Huh, H. (2012). Digit ratio and celebrity worship. Personality and Individual Differences, 52, 265-268.

Hyman, M. R., \& Sierra, J. J. (2010). Idolizing sport celebrities: A gateway to psychopathology? Young Consumers, 11(3), 226-238.

Jung, J., \& Hwang, C. S. (2016). Associations between attitudes toward cosmetic surgery, celebrity worship, and body image among south Korean and US female college students. Fashion and Textiles, 3, 17.

Karniol, R. (2001). Adolescent females' idolization of male media stars as a transition into sexuality. Sex Roles, 44(1-2), 61-77.

Kosenko, K. A., Binder, A. R., \& Hurley, R. (2016). Celebrity influence and identification: A test of the Angelina effect. Journal of Health Communication, 21(3), 318-326.

Larson, R. (1995). Secrets in the bedroom: Adolescents' private use of media. Journal of Youth and Adolescence, 24(5), 535-550.

Leets, L., de Becker, G., \& Giles, H. (1995). FANS: Exploring expressed motivations for contacting celebrities. Journal of Language and Social Psychology, 14(1-2), 102-123.

Lewallen, J., Miller, B., \& Behm-Morawitz, E. (2016). Lifestyles of the rich and famous: Celebrity media diet and the cultivation of emerging adults' materialism. Mass Communication \& Society, 19(3), 253-274.

Liu, J. K. K. (2013). Idol worship, religiosity, and self-esteem among university and secondary students in Hong Kong. Discovery - SS Student E-journal, 2, 15-28.

Malik, G., \& Guptha, A. (2014). Impact of celebrity endorsements and brand mascots on consumer buying behavior. Journal of Global Marketing, 27(2), 128-143.

Maltby, J. (2004). Celebrity and religious worship: A refinement. The Journal of Psychology, 138(3), 286-288.

Maltby, J., \& Day, L. (2011). Celebrity worship and incidence of elective cosmetic surgery: Evidence of a link among young adults. Journal of Adolescent Health, 49, 483-489.

Maltby, J., \& Day, L. (2017). Regulatory motivations in celebrity interest: Self-suppression and self-expansion. Psychology of Popular Media Culture, 6(2), 103-112.

Maltby, J., \& McCutcheon, L. E. (2001). Correlations between scores on attitudes toward celebrities and authoritarianism. Psychological Reports, 88, 979-980.

Maltby, J., McCutcheon, L. E., Ashe, D. D., \& Houran, J. (2001). The self-reported psychological wellbeing of celebrity worshippers. North American Journal of Psychology, 3(3), 441-452.

Maltby, J., Houran, J., Lange, R., Ashe, D., \& McCutcheon, L. E. (2002). Thou shalt worship no other gods - Unless they are celebrities: The relationship between celebrity worship and religious orientation. Personality and Individual Differences, 32, 1157-1172.

Maltby, J., Houran, J., \& McCutcheon, L. E. (2003). A clinical interpretation of attitudes and behaviours associated with celebrity worship. Journal of Nervous and Mental Disease, 191(1), 25-29.

Maltby, J., Day, L., McCutcheon, L. E., Gillett, R., Houran, J., \& Ashe, D. D. (2004a). Personality and coping: A context for examining celebrity worship and mental health. British Journal of Psychology, 95, 411-428.

Maltby, J., Day, L., McCutcheon, L. E., Martin, M. M., \& Cayanus, J. L. (2004b). Celebrity worship, cognitive flexibility, and social complexity. Personality and Individual Differences, 37, 1475-1482

Maltby, J., Giles, D. C., Barber, L., \& McCutcheon, L. E. (2005). Intensepersonal celebrity worship and body image: Evidence of a link among female adolescents. British Journal of Health Psychology, $10,17-32$.

Maltby, J., Day, L., McCutcheon, L. E., Houran, J., \& Ashe, D. (2006). Extreme celebrity worship, fantasy proneness and dissociation: Developing the measurement and understanding of celebrity worship within a clinical personality context. Personality and Individual Differences, 40, 273-283. 
Maltby, J., McCutcheon, L. E., \& Lowinger, R. J. (2011). Brief report: Celebrity worshipers and the five-factor model of personality. North American Journal of Psychology, 13(2), 343-348.

Martin, M. M., Cayanus, J. L., McCutcheon, L. E., \& Maltby, J. (2003). Celebrity worship and cognitive flexibility. North American Journal of Psychology, 5, 75-80.

McCarley, N. G., \& Escoto, C. A. (2003). Celebrity worship and psychological type. North American Journal of Psychology, 5(1), 117-120.

McCutcheon, L. E. (2002). Are parasocial relationship styles reflected in love styles? Current Research in Social Psychology, 7(6), 82-93.

McCutcheon, L. E. (2003). Machiavellianism, belief in a just world, and the tendency to worship celebrities. Current Research in Social Psychology, 8(9), 131-138.

McCutcheon, L. E., \& Maltby, J. (2002). Personality attributions about individuals high and low in the tendency to worship celebrities. Current Research in Social Psychology, 7(19), 325-338.

McCutcheon, L. E., \& Richman, H. (2016). Do religious skeptics differ from religious believers in their interest in celebrities? Implicit Religion, 19(2), 225-235.

McCutcheon, L. E., Lange, R., \& Houran, J. (2002). Conceptualization and measurement of celebrity worship. British Journal of Psychology, 93, 67-87.

McCutcheon, L. E., Ashe, D. D., Houran, J., \& Maltby, J. (2003). The cognitive profile of individuals who tend to worship celebrities. The Journal of Psychology, 137(4), 309-322.

McCutcheon, L. E., Aruguete, M., Scott Jr., V. B., \& VonWaldner, K. L. (2004). Preference for solitude and attitude toward one's favorite celebrity. North American Journal of Psychology, 6(3), 499-506.

McCutcheon, L. E., Scott Jr., V. B., Aruguete, M. S., \& Parker, J. (2006a). Exploring the link between attachment and the inclination to obsess about or stalk celebrities. North American Journal of Psychology, $8(2), 289-300$.

McCutcheon, L. E., Aruguete, M., Scott Jr., V. B., Parker, J. S., \& Calicchia, J. (2006b). The development and validation of an indirect measure of celebrity stalking. North American Journal of Psychology, 8(3), 503-516.

McCutcheon, L. E., Griffith, J. D., Aruguete, M. S., \& Haight, E. (2012). Cognitive ability and celebrity worship revisited. North American Journal of Psychology, 14(2), 383-392.

McCutcheon, L. E., Wong, M., Black, J., Maynard, D., Frey, R., \& Rich, G. (2014a). Does "irresponsibility" predict the addictive level of celebrity worship? North American Journal of Psychology, 16(3), 519-530.

McCutcheon, L. E., Lowinger, R., Wong, M., \& Jenkins, W. (2014b). Is analytic thinking related to celebrity worship and disbelief in religion? North American Journal of Psychology, 16(3), 453-462.

McCutcheon, L. E., Pope, T. J., Garove, A. R., Bates, J. A., Richman, H., \& Aruguete, M. (2015). Religious skepticism and its relationship to attitudes about celebrities, identification with humanity, and the need for uniqueness. North American Journal of Psychology, 17(1), 45-58.

McCutcheon, L. E., Rich, G., Browne, B., \& Britt, R. (2016a). The relationship between attitudes toward celebrities \& the five factor personality inventory at an elite Indian university: A brief report. North American Journal of Psychology, 18(3), 465-472.

McCutcheon, L. E., Aruguete, M., McCarley, N. G., \& Jenkins, W. J. (2016b). Further validation of an indirect measure of celebrity stalking. Journal of Studies in Social Sciences, 14(1), 75-91.

McCutcheon, L. E., Pope, T. J., Rich, G., \& Simplis, K. (2016c). Does savoring predict attendance at high school reunions and the tendency to admire celebrities? North American Journal of Psychology, 18(2), 295-306.

McCutcheon, L. E., Aruguete, M. S., Jenkins, W., McCarley, N., \& Yockey, R. (2016d). An investigation of demographic correlates of the celebrity attitude scale. Interpersona, 10(2), 161-170.
McCutcheon, L. E., Gillen, M. M., Browne, B. L., Murtagh, M. P., \& Collisson, B. (2016e). Intimate relationships and attitudes toward celebrities. Interpersona, 10(1), 77-89.

McCutcheon, L. E., Browne, B. L., Rich, G. J., Britt, R., Jain, A., Ray, I., et al. (2017). Cultural differences between Indian \& US college students on attitudes toward celebrities \& the love attitudes scale. Journal of Studies in Social Sciences, 16(1), 24-44.

Meloy, J., Sheridan, L., \& Hoffmann, J. (2008). Stalking, threatening, and attacking public figures: A psychological and behavioral analysis. Oxford: Oxford University Press.

Moher, D., Liberati, A., Tetzlaff, J., Altman, D. G., \& The PRISMA Group. (2009). Preferred reporting items for systematic reviews and meta-analyses: The PRISMA statement. PLoS Medicine, 6(7), e1000097.

Mullen, P. E., James, D. V., Meloy, J. R., Pathe, M. T., Farnham, F. R., Preston, L., et al. (2009). The fixated and the pursuit of public figures. Journal of Forensic Psychiatry and Psychology, 20(1), 33-47.

Neave, N., Laing, S., Fink, B., \& Manning, J. T. (2003). Second to fourth digit ratio, testosterone and perceived male dominance. Proceedings of the Royal Society B, 270, 2167-2172.

North, A. C., \& Hargreaves, D. J. (2005). Brief report: Labelling effects on the perceived deleterious consequences of pop music listening. Journal of Adolescence, 28(3), 433-440.

North, A. C., \& Hargreaves, D. J. (2006). Problem music and selfharming. Suicide and Life-threatening Behavior, 36(5), 582-590.

North, A. C., Desborough, L., \& Skarstein, L. (2005). Musical preference, deviance, and attitudes towards music celebrities. Personality and Individual Differences, 38, 1903-1914.

North, A. C., Sheridan, L., Maltby, J., \& Gillett, R. (2007). Attributional style, self-esteem, and celebrity worship. Media Psychology, 9(2), 291-308.

Obst, P., Zinkiewicz, L., \& Smith, S. G. (2002). Sense of community in science fiction fandom, Pt 1: Understanding sense of community in an international community of interest. Journal of Community Psychology, 30, 87-103.

Price, J. L., Lowinger, R. J., Jenkins, W., \& McCutcheon, L. E. (2014). The stigmatization of people with a history of mental illness by those who admire celebrities. North American Journal of Psychology, 16(2), 253-260.

Raviv, A., Bar-Tal, D., Raviv, A., \& Ben-Horin, A. (1996). Adolescent idolization of pop singers: Causes, expressions, and reliance. Journal of Youth and Adolescence, 25(5), 631-650.

Redmond, S. (2016). The passion plays of celebrity culture. European Journal of Cultural Studies, 19(3), 234-249.

Reeves, B., \& Nass, C. (1996). The media equation: How people treat computers, television, and new media like real people and places. New York: Cambridge University Press.

Reeves, R. A., Baker, G. A., \& Truluck, C. S. (2012). Celebrity worship, materialism, compulsive buying, and the empty self. Psychology \& Marketing, 29(9), 674-679.

Reyes, M. E. S., Santiago, A. G. F., Domingo, A. J. A., Lichingyao, E. N., Onglengco, M. N. M., \& McCutcheon, L. E. (2016). Fandom: Exploring the relationship between mental health and celebrity worship among Filipinos. North American Journal of Psychology, 18(2), 307-316.

Roberts, K. A. (2007). Relationship attachment and the behaviour of fans towards celebrities. Applied Psychology in Criminal Justice, 3(1), $54-74$.

Sansone, R. A., \& Sansone, L. A. (2014). "I'm your number one fan" - A clinical look at celebrity worship. Innovations in Clinical Neuroscience, 11(1-2), 39-43.

Scharf, M., \& Levy, M. (2015). The contribution of familial characteristics and idolization to children's body and eating attitudes. Journal of Child and Family Studies, 24, 1943-1954. 
Sheridan, L., Maltby, J., \& Gillett, R. (2006). Pathological public figure preoccupation: Its relationship with dissociation and absorption. Personality and Individual Differences, 41, 525-535.

Sheridan, L., North, A., Maltby, J., \& Gillett, R. (2007). Celebrity worship, addiction and criminality. Psychology, Crime \& Law, 13(6), 559-571.

Stever, G. S. (2011a). Fan behavior and lifespan development theory: Explaining Para-social and social attachment to celebrities. Journal of Adult Development, 18, 1-7.

Stever, G. S. (2011b). Celebrity worship: Critiquing a construct. Journal of Applied Social Psychology, 41(6), 1356-1370.

Stever, G. S. (2017). Evolutionary theory and reactions to mass media: Understanding parasocial attachment. Psychology of Popular Media Culture, 6(2), 95-102.

Stever, G. S., \& Lawson, K. (2013). Twitter as a way for celebrities to communicate with fans: Implications for the study of parasocial interaction. North American Journal of Psychology, 15(2), 339-354.

Swami, V., Taylor, R., \& Carvalho, C. (2009). Acceptance of cosmetic surgery and celebrity worship: Evidence of associations among female undergraduates. Personality and Individual Differences, 47, 869-872.

Swami, V., Chamorro-Premuzic, T., Mastor, K., Siran, F. H., Said, M. M. M., Jaafar, J., et al. (2011a). Celebrity worship among university students in Malaysia: A methodological contribution to the celebrity attitude scale. European Psychologist, 16(4), 334-342.

Swami, V., Taylor, R., \& Carvalho, C. (2011b). Body dissatisfaction assessed by the photographic figure rating scale is associated with sociocultural, personality, and media influences. Scandinavian Journal of Psychology, 52, 57-63.

Tajfel, H., \& Turner, J. C. (1986). The social identity theory of intergroup behavior. Psychology of Intergroup Relations, 5, 7-24.

Tengco-Pacquing, C., Cayubit, R., Reyes, M., Agnes, M. C., \& McCutcheon, L. E. (2014). The experience of power and the tendency to worship celebrities. North American Journal of Psychology, 16(2), 225-234.

Veer, E., Becirovic, I., \& Martin, B. A. (2010). If Kate voted conservative, would you? The role of celebrity endorsements in political party advertising. European Journal of Marketing, 44(3-4), 436-450.

Vega, C. B. C., Magpantay, J. A. G., Zapanta, J. Y. R., Tolentino, R. M. N., Varona, A. A., Tengco-Pacquing, C., et al. (2013). A brief report on celebrity attitude scale data collected in the Philippines. North American Journal of Psychology, 15(1), 213-214.

Wang, J.-S., Cheng, Y.-F., \& Chu, Y.-L. (2013). Effect of celebrity endorsements on consumer purchase intentions: Advertising effect and advertising appeal as mediators. Human Factors and Ergonomics in Manufacturing \& Service Industries, 23(5), 357-367.

Wann, D. L. (1995). Preliminary validation of the sport fan motivation scale. Journal of Sport \& Social Issues, 19(4), 377-396.

Weiner, B. (1986). An attributional theory of motivation and emotion. New York: Springer-Verlag.

Yue, X. D., \& Cheung, C. K. (2000). Selection of favourite idols and models among Chinese young people: A comparative study in Hong Kong and Nanjing. International Journal of Behavioral Development, 24(1), 91-98. 